\title{
Innovative experimental and finite element assessments of the performance of CFRP- retrofitted RC beams under fatigue loading
}

DOI 10.1515/secm-2016-0101

Received April 9, 2016; accepted November 5, 2016; previously published online March 13, 2017

Abstract: Numerous experimental studies have proven the efficiency of externally bonded fiber-reinforced polymer (FRP) systems on structural concrete elements, such as reinforced concrete (RC) beams. The current paper presents an analytical formulation of mechanical constants based on the results of experimental data, which were acquired from fatigue testing of intact and CFRPretrofitted RC beams. A total of six scaled RC beams were prepared for the test, three of which were strengthened with carbon fiber-reinforced polymers (CFRPs). A specific finite element model coupled with experimental results from the proposed RC beams made it possible to compare the theoretical and experimental fatigue behavior of RC beams with and without composite reinforcement. The developed numerical model was then extended to evaluate a higher number of fatigue load cycles, as recommended by bridge codes. This was carried out to monitor the performance of CFRP-retrofitted RC beams in terms of flexural stiffness deterioration and damage propagation. The relationships presented in this paper were calibrated to the tested specimens. Moreover, they were useful for the design of RC and CFRP-retrofitted RC beams and for predicting fatigue performance, including the damage behavior of constituent materials.

Keywords: CFRP-retrofitted RC beams; experimental and finite element investigations; externally bonded fiber reinforced polymer systems; high cycle fatigue; propagation of tension cracks.

\footnotetext{
*Corresponding author: Ata Hojatkashani, Assistant Professor, Department of Civil Engineering, Islamic Azad University, South Tehran Branch, Tehran, Iran, e-mail: ata_hojat@aut.ac.ir Mohammad Zaman Kabir: Department of Civil and Environmental Engineering, Amirkabir University of Technology, Tehran, Iran. http://orcid.org/0000-0002-8318-4583
}

\section{Introduction}

Recently, externally bonded fiber-reinforced polymers have been widely used to rehabilitate reinforced concrete (RC) structures [1, 2]. Numerous research, including experimental, analytical and finite element approaches, have been conducted to investigate the monotonic behavior of carbon fiber-reinforced polymer (CFRP)-strengthened RC beams [3-9]. Many significant parameters must be considered in the research regarding CFRP-retrofitted RC beams, and these include premature failure modes, which result from either interfacial or end plate stresses [10] or crack propagation [11]. In addition to the mentioned critical parameters, the evolution of uniform materials during cyclic fatigue loading is significant and must be more thoroughly investigated given the highly cyclical behavior of such structures. Fatigue is the process of progressive changes to the permanent internal structure of a material subjected to repetitive stresses. These changes may be damaging, resulting in progressive crack growth and, ultimately, complete fracture [12]. Other research have focused on the reduced durability of bent RC beams, which are strengthened with composite materials and subjected to cyclic loading. Additionally, beam rigidity, cracking morphology, the interaction of reinforcement components with regards the bond uniformity of the entire structure, and the durability of the bond under cyclic loads, have been investigated in previous research $[13,14]$. A previous research presented an analytical procedure incorporating the cyclical behavior of concrete and the degradation of flexural stiffness [15]. The results presented in this paper also provided an experimental investigation, in which $\mathrm{RC}$ beams were strengthened with glass fabrics and subjected to fatigue loading. The comparison showed that the analytical model provided a reasonably accurate prediction of the deflections for both the reinforced beams and RC beams retrofitted with composites. This model was first defined for concrete prisms under centric and eccentric compression before being applied to concrete-steel structures.

The current paper presents a relatively simple methodology to study the fatigue behavior of concrete in 
compression and focuses on $\mathrm{RC}$ members under flexure. In this research, numerical examples that reproduce the evolution of stresses and strains in RC short columns are presented.

One of the important aspects of fatigue examination is the material damage index. Concrete damage during fatigue loading is important because, as a function of load cycles, it can lead to the evolution of the modulus of elasticity. Calibrated experimental results based on a few studies can be used to modify the modulus of elasticity [16]. Furthermore, in recent works, calibrated formulations have been generated based on experimental tests on concrete and CFRP to calculate the changes in the modulus of elasticity of constituent elements in CFRPretrofitted beams with fatigue loading $[17,18]$.

After considering previous works on the fatigue behavior of intact and CFRP-retrofitted RC beams, it has been realized that more detailed research on the subject is required. Hence, the present study investigates the effect of the range of fatigue loading on the ultimate strength capacity, stiffness, deformation, and failure mode of CFRP-strengthened concrete beams using both experimental and numerical approaches. This study also attempts to calibrate the fatigue experimental results to fit an analytical expression for the damage process. Additionally, reasonable comparisons between the numerical and experimental results are presented.

\section{Experimental program}

This section describes the main characteristics of the tested specimens, the properties of their constituent materials, the experimental loading apparatus, the instrumentation, and the testing sequences. In this study, six $\mathrm{RC}$ beams were prepared for testing, three of which were
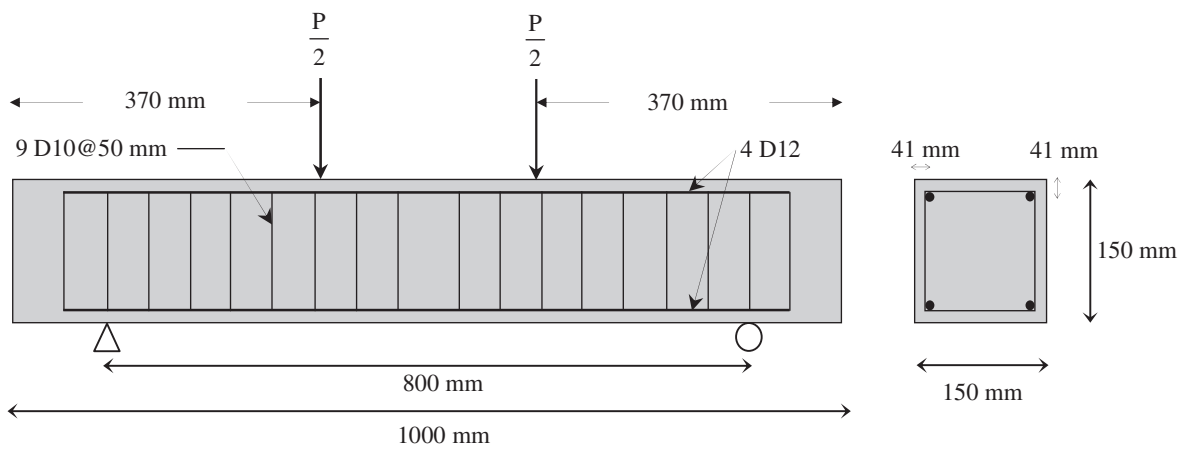

Figure 1: Typical geometry of a concrete beam and reinforcement bar. retrofitted with CFRP fabrics. The concrete was produced from a mixture of water, cement, sand, and aggregate with ratios (by mass) of $0.55: 1: 2.2: 1.7$, respectively. The average compressive strength of the concrete was determined to be approximately $50 \mathrm{MPa}$ using a series of standard cylindrical specimens of $150 \mathrm{~mm}$ in diameter and $300 \mathrm{~mm}$ in height. The typical geometry and reinforcement of the tested beams are illustrated in Figure 1.

A longitudinal reinforcement with a diameter of $12 \mathrm{~mm}$ exhibited a yield stress of approximately $365 \mathrm{MPa}$ and a Young's modulus of approximately $205 \mathrm{GPa}$. Stirrups were made of steel bars with a diameter of $10 \mathrm{~mm}$, yield stress of $260 \mathrm{MPa}$, and Young's modulus of $200 \mathrm{GPa}$. The wet lay-up strengthening procedure was used to apply two layers of unidirectional CFRP sheets to the tension face of the concrete beams, which strengthened the specimens in flexure. Then, U-wraps of CFRP sheets were attached to the supports to prevent the longitudinal CFRP fabric from debonding at the free edge. Sika Wrap ${ }^{\circledR}-200 \mathrm{C}$ carbon fibers were used in the CFRP sheets, and a type of Sikadure ${ }^{\circledR}-300$ epoxy resin was used as the adhesive to bond the CFRP sheets to the concrete substrate. Both products were produced by the Sika Company. The specifications of the carbon fiber, the epoxy resin, and the assembled CFRP sheet are presented in Table 1.

A notch with a length of $15 \mathrm{~mm}$ was made at the middle bottom surface on all of the studied RC beams. The retrofitted specimens were strengthened with two layers of $1 \mathrm{~mm}$ thick CFRP at the tension face of the specimens. A schematic representation of the retrofitted $\mathrm{RC}$ beams is shown in Figure 2.

A servo-hydraulic universal DARTEC 1900 instrument (Zwick/Roell, Germany) was used for the tests. Prior to the testing, strain gauges were attached to the specimens. Two types of strain gauges were used to record the data; the PFL was used for the concrete, and the BFLA type was used for the composite. Both types of gauges are produced by the 
Table 1: Mechanical properties of carbon fiber, epoxy resin, and CFRP composite.

\begin{tabular}{lrrr}
\hline & $\begin{array}{r}\text { Tensile } \\
\text { strength (MPa) }\end{array}$ & $\begin{array}{r}\text { Tensile modulus } \\
\text { of elasticity (MPa) }\end{array}$ & $\begin{array}{r}\text { Failure } \\
\text { strain (\%) }\end{array}$ \\
\hline Fibers & 3900 & 230,000 & 1.5 \\
Epoxy resin & 40 & 3500 & 1.5 \\
CFRP composite & 500 & 50,000 & 1 \\
\hline
\end{tabular}

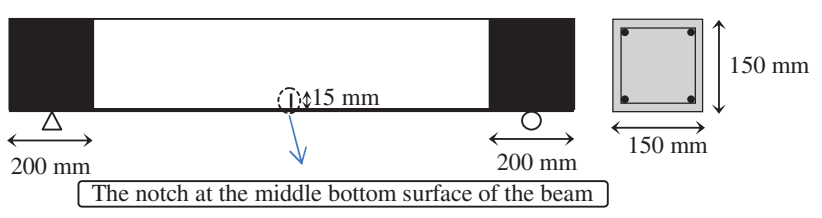

Figure 2: Schematic representation of a CFRP-strengthened RC beam.

TML Company, Japan. A linear variable differential transformer (LVDT) at the bottom middle section of the specimens was used to record the deflections. Additionally, a load cell was placed between top surface of the specimens and the machine grip. All data, which consisted of strains (using strain gauges), mid-span deflections (using LVDT), and loads (using load cells), were recorded with a TML dynamic data logger.

Next, all beams were primarily subjected to a fourpoint bending configuration with a simply supported span of $850 \mathrm{~mm}$ (Figure 1). The specimens were then subjected to fatigue loading to investigate the effects of cycle number on load deflection and strain response. The fatigue loading frequency was $0.5 \mathrm{~Hz}$ with a recording frequency of every $0.2 \mathrm{~s}$. Selection of the current frequency was based on the following two conditions: the testing frequency must be within the frequency range of vehicle traffic loading, and the servo-hydraulic machine must function properly under the selected testing frequency.

The specimens were tested at a constant amplitude of $6.5-65 \mathrm{kN}$ for the control RC beams and $8.5-85 \mathrm{kN}$ for the CFRP-retrofitted beams with a constant R-ratio of 0.1. Selection of the current amplitudes was based on the service loading limits of each of the intact RC beams and the CFRP-retrofitted RC specimens. Figure 3 presents the test setup, equipment, and position of strain gauges mounted on all the specimens. The maximum number of cycles allowed by the test apparatus, 50,000, were performed during the experiments. An introduction of the loading procedure and failure modes of tested beams, presented in Table 2, is discussed thoroughly in the results and discussion section.

\section{Finite element analysis}

To verify the experimental test results, a numerical model using the FE program ABAQUS was generated. Mechanical characteristics of the modeled materials were introduced as the following. The concrete damaged plasticity model was used to analyze the concrete. The modified Hognestad model [19] was used as the nonlinear compressive stress-strain relation for concrete. The stress-strain diagram of this model is illustrated in Figure 4.

For the tensile behavior of concrete, the damaged continuum plasticity model proposed by [20] was applied. For concrete, the model assumes that the two main failure mechanisms are tensile cracking and compressive crushing of the concrete material. The nonlinear model applied in the software is capable of elastic-isotropic modeling, which includes both plastic isotropic-compressive and isotropic-tensile behavior. For the steel rebar, elastic-perfect plastic behavior was applied. A two-layer CFRP sheet was attached to the tensile side and assumed to behave linearly elastic during the FE analysis. Moreover, the adhesive layer between concrete substrate and the CFRP layer was modeled, and its behavior was assumed to be elasticperfect plastic. The remaining details of the mechanical properties, such as tensile strength, compressive strength, and modulus of elasticity, have been explained previously according to Section 2 (experimental program) and also introduced in Table 1.

A total of 6460 8-node brick C3D8R elements with a size of $20 \mathrm{~mm}$ were used for the concrete. Concrete elements were refined to a size of $3.75 \mathrm{~mm}$ around the crack. For the CFRP layer, a total of 450 4-node shell S4R elements with a size similar to that of the concrete were applied. Finally, a total of 540 2-node 3D truss elements, T3D2, were applied to model the steel rebar. The cracked part at the middle section of the beam was modeled as a flaw. Figure 5 demonstrates the FE model. FEM analysis was conducted to analyze fatigue, and the data were presented at every 10,000 cycles for cycles 10,000-50,000. The results for each cycle, including deformed and cracked element data, were used as inputs for the analysis in the proceeding cycle by applying the RESTART capability of the software. Concrete cracking was generated using a concrete damage plasticity model. Material degradation, significant in cyclic fatigue analysis, was applied in the model. For the numerical analysis of fatigue, the prescribed damage and material degradation models were applied for every load cycle, as indicated in Section 4. Damage index was presented for the unloading branches of the fatigue load 

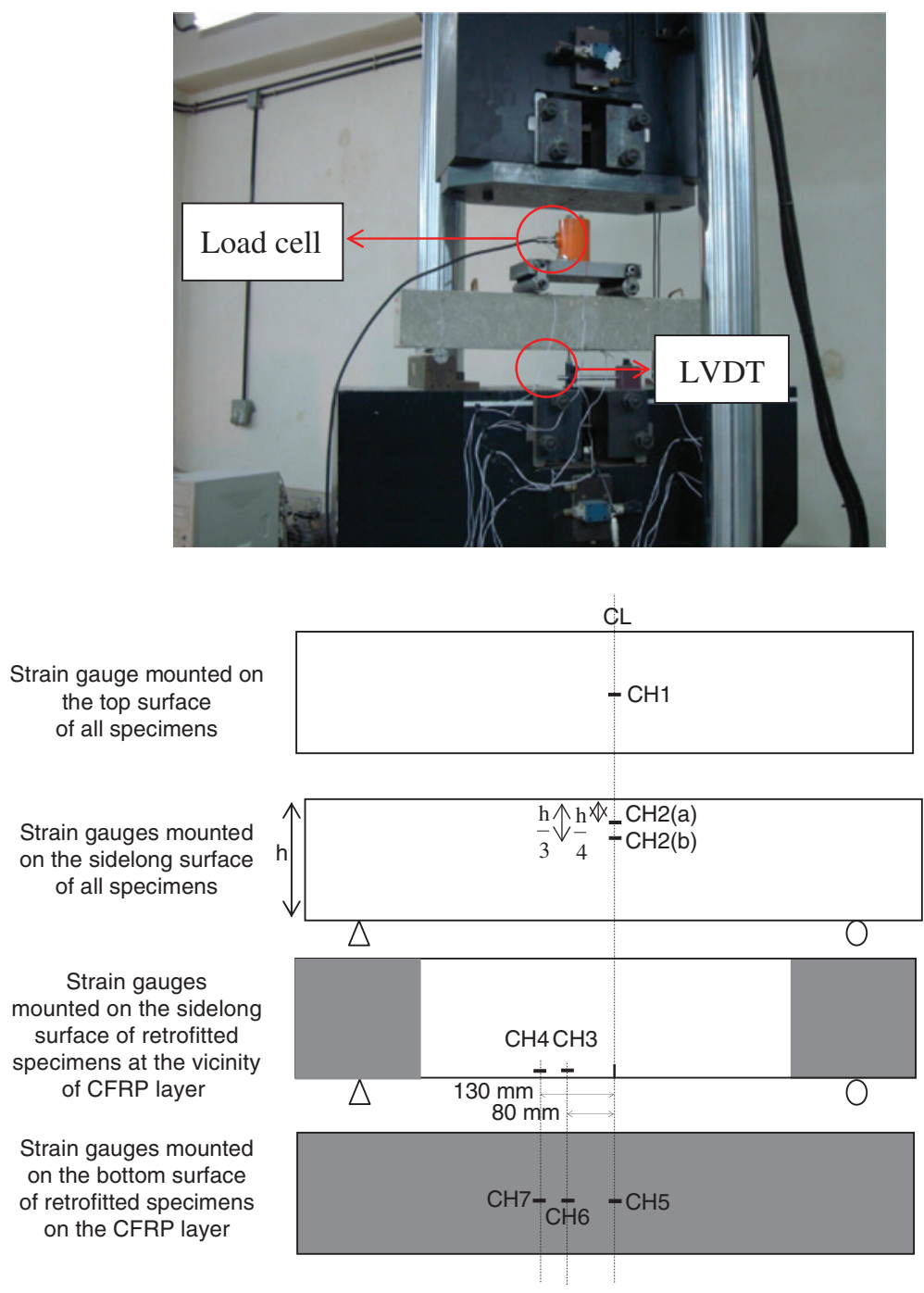

Figure 3: Fatigue test setup and position of strain gauges mounted on all the specimens.

Table 2: Introduction of loading procedures and failure modes of tested specimens.

\begin{tabular}{|c|c|c|}
\hline \multirow[t]{2}{*}{ Type of specimen } & \multicolumn{2}{|l|}{ Loading/Failure } \\
\hline & Loading procedure & Failure mode \\
\hline Intact RC beam & Pre-fatigue monotonic loading & Initial cracking (At the limit of elastic behavior) \\
\hline Intact RC beam & $\begin{array}{l}\text { Cyclic fatigue loading with } \\
\text { constant amplitude of } 6.5-65 \mathrm{kN}\end{array}$ & Distribution of cracks and degradation of beam flexural stiffness \\
\hline Intact RC beam & Post-fatigue monotonic loading & Propagation of cracks incorporated with compressive concrete crushing \\
\hline CFRP-retrofitted RC beam & Pre-fatigue monotonic loading & Initial cracking (At the limit of elastic behavior) \\
\hline CFRP-retrofitted RC beam & $\begin{array}{l}\text { Cyclic fatigue loading with } \\
\text { constant amplitude of } 8.5-85 \mathrm{kN}\end{array}$ & $\begin{array}{l}\text { Distribution of cracks, degradation of beam flexural stiffness and local } \\
\text { debonding of the CFRP layer from concrete substrate }\end{array}$ \\
\hline CFRP-retrofitted RC beam & Post-fatigue monotonic loading & Propagation of cracks incorporated with compressive concrete crushing \\
\hline
\end{tabular}

cycles. However, as the load level was obtained at the service limit, the damage index for compression was applied as $d_{c}=0$. Softening occurred in tension, and $d_{t}$ was applied to the model. During the tensile behavior of concrete, damage versus strain was introduced as the damage parameter, and both the damage parameter and cracking strain were set to be 0 . The subsequent points for the damage parameter and cracking strain were 0.98 


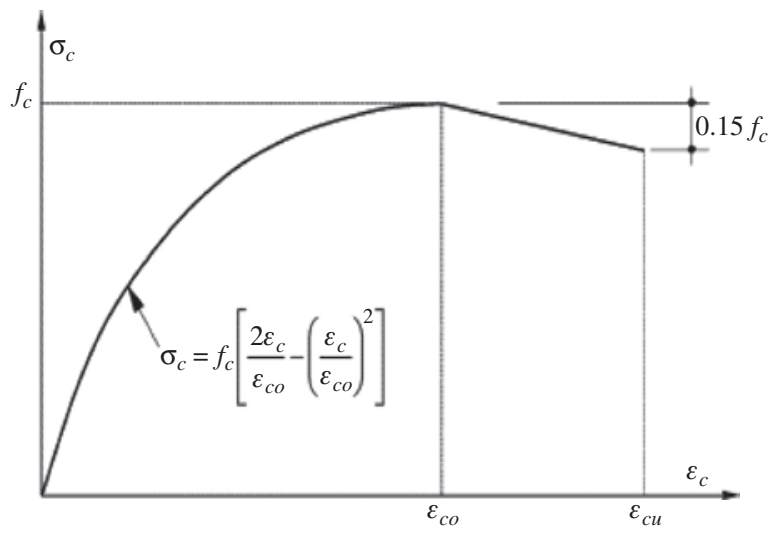

Figure 4: Stress-strain curve for ordinary concrete proposed by [19].

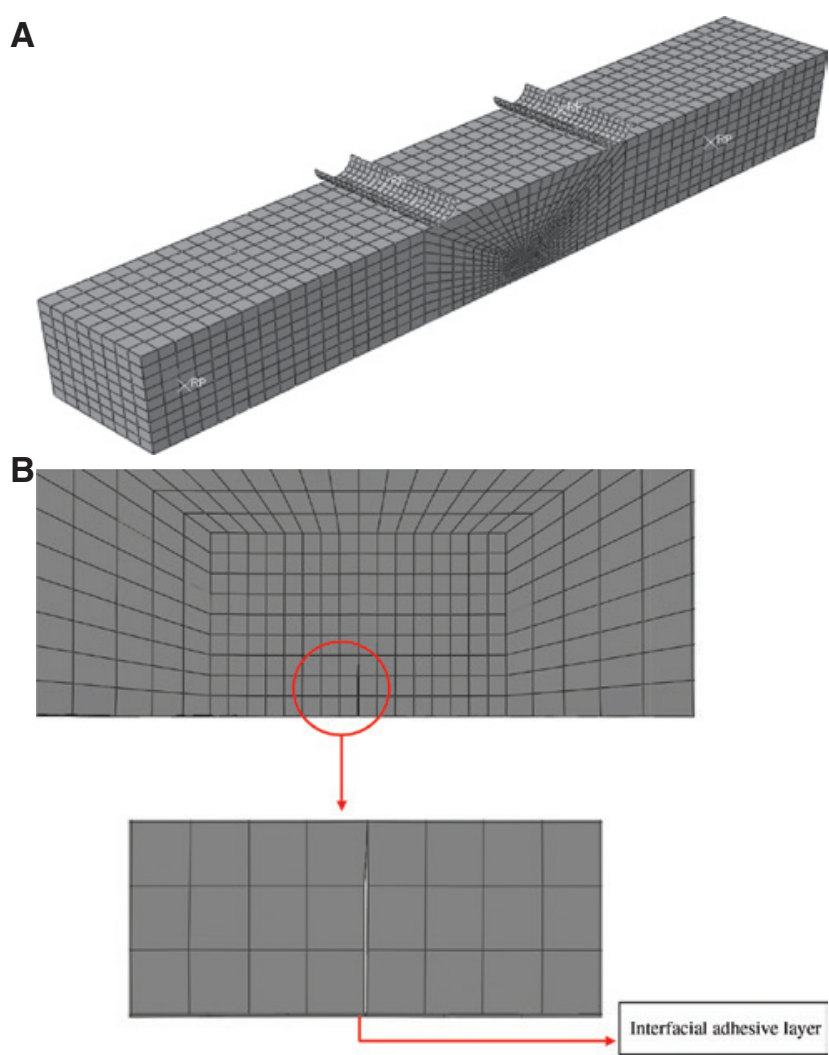

Figure 5: Finite element model of the tested beams and fine mesh generation around the crack tip zone.

(A): Finite element model representation. (B): Fine mesh around the crack tip in the RC beam FE model.

and 0.0008 , respectively. These values were chosen to satisfy the criteria for both the numerical FE results and the experimental data.

The current material modification was implemented for concrete and CFRP using relations from previous studies and the present study. The results are discussed in detail in the following section.

\section{Fatigue properties of the materials}

Recently, some researchers have focused on the evolution of CFRP-retrofitted RC beams under fatigue loading. Among them, the relation presented by $[21,22]$ is notable and can be used to predict changes to the Young's modulus induced by fatigue loading as

$$
E_{C N}=\frac{\sigma_{C \max }}{\frac{\sigma_{C \max }}{E_{C}}+\varepsilon_{C N}},
$$

where $\sigma_{C \max }$ denotes the maximal stress in concrete in compression under fatigue loading, $E_{C}$ is the initial Young's modulus of the concrete, and $\varepsilon_{C N}$ is the increase in concrete strain for $\mathrm{N}$ load cycles.

The evolution of compressive strain $\left(\varepsilon_{C N}\right)$ as a function of the number of load cycles $(\mathrm{N})$ is given by [21, 22]

$$
\varepsilon_{C N}=8.417 \times 10^{-6} \cdot\left(\frac{\sigma_{C}^{m}}{f_{C}}\right) \cdot\left[\left(\frac{\mathrm{N}}{w}\right)^{\frac{1}{3}}+3.87 \cdot\left(\frac{\sigma_{C}^{r}}{f_{C}}\right) \cdot\left(\frac{\mathrm{N}}{9.75}\right)^{\frac{1}{3}}\right] \text {, }
$$

where $w$ is the load cycle frequency, $\sigma_{c}^{r}=\sigma_{\text {max }}-\sigma_{\text {min }}$ is the stress cycle amplitude, $\sigma_{C}^{m}=\left(\sigma_{\max }-\sigma_{\text {min }}\right)^{\frac{1}{2}}$ is the average loading stress, and $f_{C}$ is the compressive strength of concrete.

The relationship between load cycle and the evolution of concrete compressive strain, which was estimated by using Eq. 2 [21, 22] and measured from tests performed in the current paper, can be found in Figure 6.

Given the concrete strain at each cycle, and using the concrete compressive stress-strain relation, [23], the

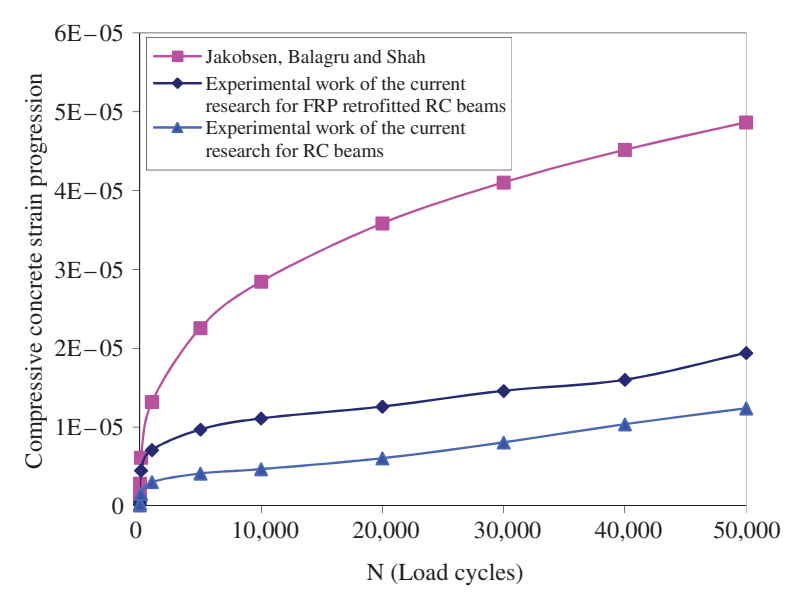

Figure 6: Progression of maximum compressive strain of concrete versus load cycle during fatigue testing. 
concrete stress at each cycle is obtained at each cycle from the relation given by

$$
f_{C}=\frac{n f_{C}^{\prime}\left(\varepsilon_{C} / \varepsilon_{C}^{\prime}\right)}{n-1+\left(\varepsilon_{C} / \varepsilon_{C}^{\prime}\right)^{n k}}
$$

where $f_{C}$ is the concrete stress, $f_{C}^{\prime}$ is the unconfined compressive strength of concrete (i.e. standard cylindrical strength), $\varepsilon_{C}$ is the concrete strain, $\varepsilon_{C}^{\prime}$ is the concrete strain at $f_{C}^{\prime}, n=0.8+f^{\prime}{ }_{C} / 17$, and $k=\left(0.67+f^{\prime}{ }_{C} / 62\right)>1$ for $\left(\varepsilon_{C} / \varepsilon_{C}^{\prime}\right)>1$, otherwise $k=1$. Then, the altered Young's modulus can be predicted. This relation reduces the compressive concrete stress as a function of the number of load cycles. This result is evident in the $\mathrm{S}-\mathrm{N}$ curve, which is important in the fatigue design of structures and implemented in the FEM analysis for the current research.

Considering the evolution of the CFRP elastic modulus, the relationship between Young's modulus of the composite and number of load cycles was obtained and fitted using a common Wohler law given by

$$
\mathrm{E}_{\mathrm{f}}(\mathrm{N})=\alpha \cdot \ln (\mathrm{N})+\beta .
$$

According to [24, 25], the values for parameters $\alpha$ and $\beta$ are $\alpha=-507$ and $\beta=70,227$.

Due to the limitations of the testing apparatus, experiments were performed using applied loads at a specified design level. However, the study was extended to investigate fatigue loading up to specimen failure. Using the adopted finite element method, the failure cycles for both intact and CFRP-retrofitted RC beams were estimated using the following procedure.

\subsection{RC beams}

The adopted RC beam for the current study was similar to those used in [26] and had the ratio of maximum applied fatigue loading to ultimate flexural loading given by

$$
\frac{P_{\max }}{P_{u l t}}=\frac{65}{110}=0.59 \text {. }
$$

For this ratio, the tensile steel rebar yields prior to the primary failure mode. The number of cycles to failure was calculated using the relation proposed by [27]

$$
\log \left(\mathrm{N}_{\mathrm{F}}\right)=6.969-0.0055 \sigma_{\mathrm{r}},
$$

where $\mathrm{N}_{\mathrm{F}}$ is the number of cycles at the instant of failure, and $\sigma_{\mathrm{r}}$ is the range of tensile stress of the steel rebar. From the FEM analysis, the tensile stress was determined to be as $\sigma_{r} \cong 300 \mathrm{MPa}$. Therefore, the number of cycles to failure was estimated to be as $N_{F}=200,000$.

\subsection{CFRP-retrofitted RC beams}

The same procedure accommodates CFRP-retrofitted RC beams when the relation between the maximum applied fatigue load to the ultimate bearing load is considered. The relation is given by

$$
\frac{P_{\max }}{P_{u l t}}=\frac{85}{160}=0.53
$$

For this case, primary failure can be considered as the tensile yielding of the steel rebar. However, according to [26], debonding of the CFRP sheet from the concrete substrate should also be assumed in the analysis. The current FEM solution represented the failure cycle of CFRP-retrofitted RC specimens. Moreover, knowing that $\sigma_{r} \cong 250 \mathrm{MPa}$ from the FEM analysis, and that the number of cycles to failure can be predicted using Equation 5, the number of cycles to failure was determined to be $\mathrm{N}_{\mathrm{F}}=400,000$.

\section{Results and discussion}

\subsection{Overall discussion on experimental and finite element examinations of fatigue tests}

The results are presented in terms of material properties, i.e. concrete compressive and tensile stress versus cycle number, mid-span load deflection curves, crack growth, and $\mathrm{RC}$ beam flexural degradation with fatigue loading.

Using compressive concrete strain from the experimental measurements in Eq. 3, the variation of concrete compressive stress versus load cycle number, an S-N curve, is depicted in Figure 7. This curve shows that the

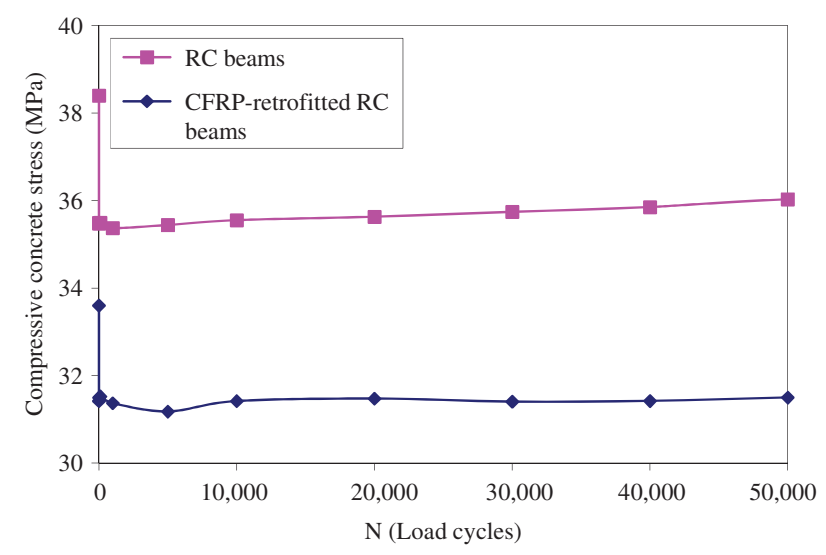

Figure 7: Experimental measurements of the maximum compressive stress for concrete versus load cycle number. 
concrete stress rapidly decreased during initial load cycles and then plateaued, which is similar to typical creep behavior. The overall reductions in concrete stress were $8 \%$ and $7 \%$ for intact and CFRP-retrofitted RC beams, respectively. The overall increase in CFRP tension-stress was approximately $10 \%$ for the considered load level.

The evolution of Young's modulus of concrete during fatigue load cycles was estimated using Eq. 1. For this procedure, the evolution of compressive concrete strain was calculated and substituted into Eq. 1. The compressive concrete strain evolution was estimated using Eq. 2 from [21, 22] and obtained from the experimental measurements performed in the current research. The initial Young's modulus of concrete was $\mathrm{E}_{0}=32 \mathrm{GPa}$. The degraded Young's modulus of concrete in the last experimental fatigue cycle (load cycle 50,000) was calculated using Eq.1, and the compressive concrete strain evolution was determined by Eq. 2 from [21, 22]. The Young's modulus was determined to be $92.9 \% \mathrm{E}_{0}$ for an intact $\mathrm{RC}$ beam and $97.62 \% \mathrm{E}_{0}$ for a CFRP-retrofitted RC beam. During the last experimental fatigue cycle, the degraded Young's modulus was estimated by Eq.1 using the evolution in compressive concrete strain obtained from experimental measurements. The degraded Young's modulus was determined to be $94.49 \% \mathrm{E}_{0}$ for an intact $\mathrm{RC}$ beam and $98.65 \% \mathrm{E}_{0}$ for a CFRP-retrofitted RC beam.

Both experimental (EXP) and finite element approaches are discussed in the following fatigue examinations. The fatigue testing procedure used in the current research consists of three stages.

\subsubsection{Pre-fatigue monotonic loading}

At the beginning of the tests and throughout the range of service loads, the specimens were subjected to pre-fatigue monotonic loading. During this stage of loading, which was prior to the cyclic fatigue loading stage, each of the intact and CFRP-retrofitted RC beams in the specimens were subjected to quasi-static monotonic loading of the maximum design service load. As a result, major cracks were initiated and distributed. Furthermore, the cracks propagated during subsequent cyclic fatigue loading stages.

All the RC beams behaved identically when subjected to monotonic loading. Moreover, the behavior of CFRPretrofitted RC beams subjected to monotonic loading was analogous to that of the intact RC beams. However, the initial and post failure flexural stiffnesses were quite different. Figure 8 illustrates applied load versus midspan deflection under monotonic loading prior to fatigue

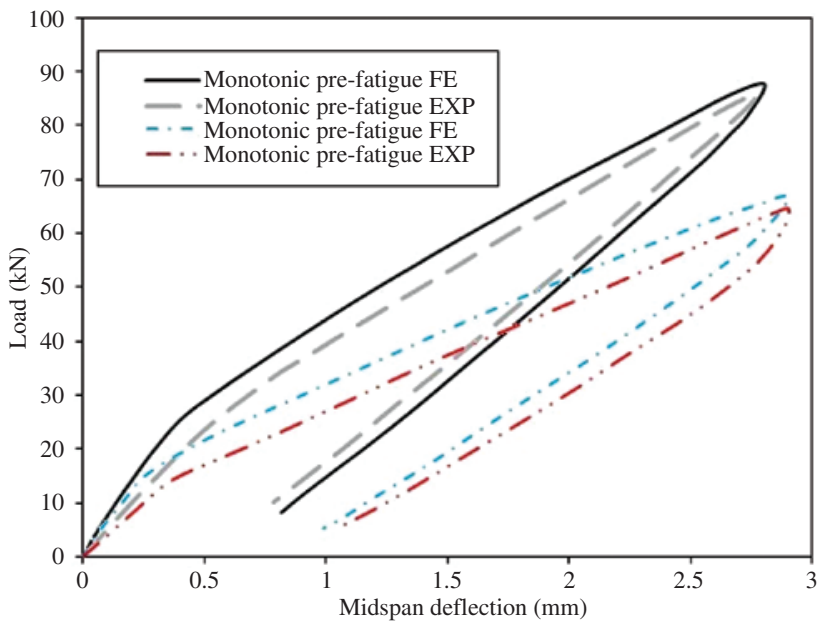

Figure 8: Pre-fatigue monotonic load-deflection curves of RC and CFRP-retrofitted RC specimens, as determined by FE and experimental examinations.

testing. The results indicated an overall correlation between the numerical FEM approaches and the experimental measurements in both cases. Load-deflection curves obtained from experimental and $\mathrm{FE}$ analysis at various stages of monotonic pre-fatigue and fatigue loadings for intact and CFRP-retrofitted RC beams were compared and presented in Figures 8 and 9, respectively. The strengthening procedure increased flexural load carrying capacity by approximately $31 \%$ and reduced mid-span deflection by $2.5 \%$. Additionally, a summary of the results from this stage is displayed in Table 3.

\subsubsection{Fatigue loading}

Typical load deflection hysteresis curves for RC control and CFRP-retrofitted beams that were experimentally subjected to 50,000 cycles are shown in Figure 9A-E, respectively. However, the numerical approach went up to 200,000 cycles for the control and either 400,000 cycles or the number of cycles up to failure for the CFRPretrofitted beam. With the exception of the pre-fatigue monotonic experiment, the first 10,000 cycle test, shown in Figure 9A, and all other cycles are illustrated in Figure 9B-E. Furthermore, tension cracks formed and propagated as the number of applied loads increased. Cracking patterns of the reference and CFRP-retrofitted RC beams after being subjected to 50,000 load cycles are presented in Figures 10 and 11, respectively. As can be seen, racks were equally distributed in the retrofitted beam compared to the control beam under identical load cycles. 
Stiffnesses of reference and CFRP-retrofitted beams were calculated after each fatigue load cycle, in order to provide a quantitative measure of the degradation of beam flexural stiffness. The stiffnesses were calculated by estimating the slope of the load-deflection curve using linear regression analysis.

For each specimen, the obtained stiffness values were normalized with respect to the post cracking stiffness of the beam before application of the fatigue loads. Figure 12 shows both experimental and FEM approaches for the degradation of stiffness normalized with respect

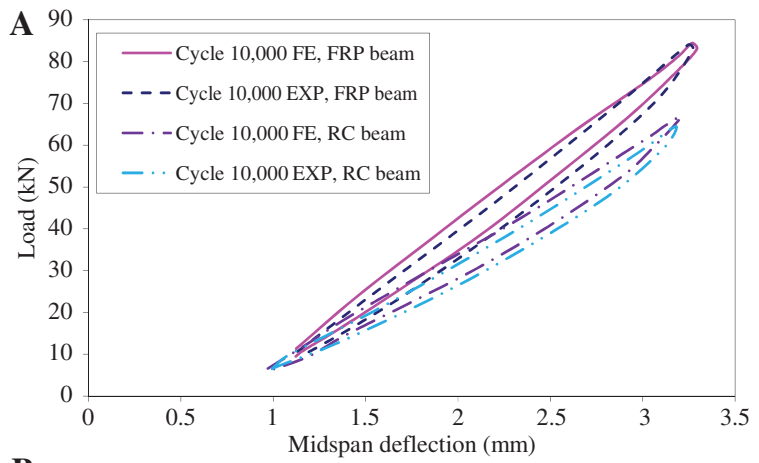

B

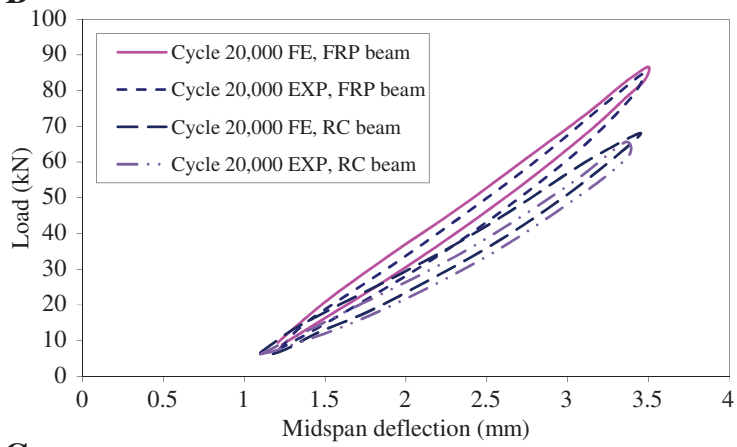

C

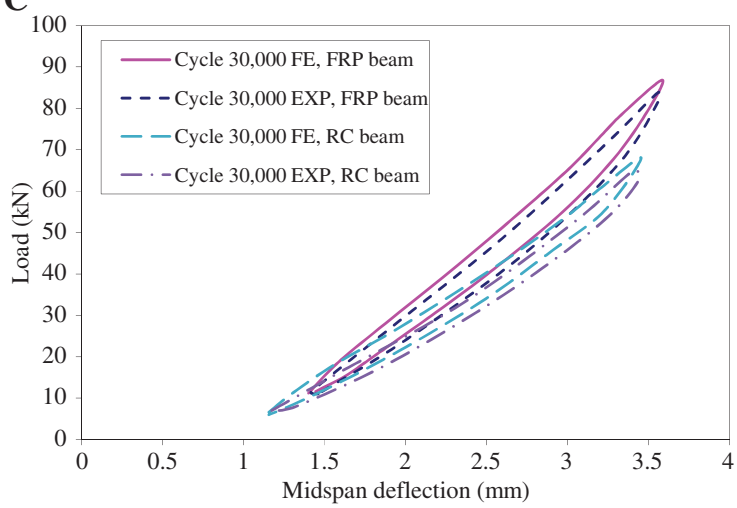

Figure 9: Load-deflection curves of RC and CFRP-retrofitted RC specimens. as determined by $\mathrm{FE}$ and experimental examinations for (A) fatigue loading at cycle 10,000, (B) fatigue loading at cycle 20,000 , (C) fatigue loading at cycle 30,000, (D) fatigue loading at cycle 40,000, and (E) fatigue loadings at cycles 50,000, 200,000, and 400,000 .
D

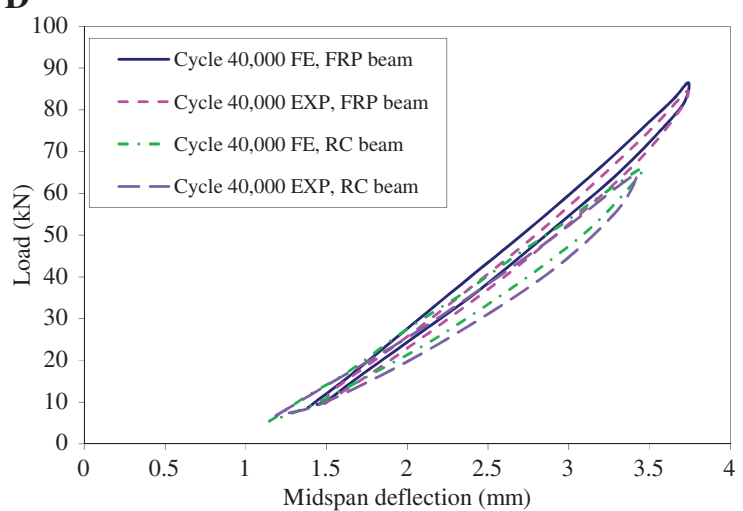

$\mathbf{E}$

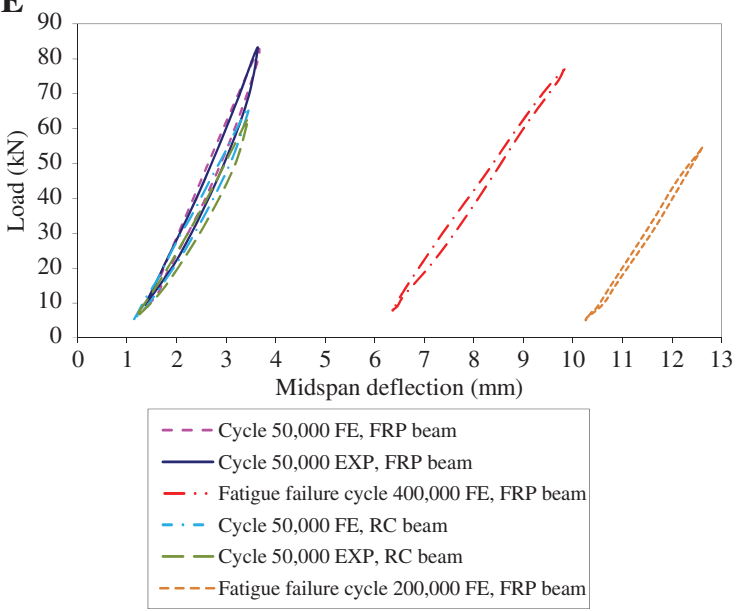

Figure 9 (continued)

to the stiffness of the beam under pre-fatigue monotonic loading. Repeated fatigue cycles caused slight but stable reductions in the stiffness and fatigue loading stress of all of the beams. The phenomena of stiffness degradation can be related to crack formation and propagation, which implies a relative slip between the concrete, steel rebar and CFRP sheets, and concrete failure at the tension zone. The adopted FEM approach was used to estimate degradation of the stiffness, and similar trends were predicted with respect to the experimental measurements. However, due to inadequacies in the complete numerical model, lower values were predicted. A range of $8 \%$ and $20 \%$ maximum degradation of stiffness was estimated for the reference beams and CFRP-retrofitted beams, respectively.

The measured and calculated longitudinal strains of CFRP-retrofitted RC beams for different load cycles are illustrated in Figure 13. Strain gauge was mounted at the bottom of the CFRP layer at the mid-span of the beam according to Figure 3. In general, as the number of load cycles increased, strain of the retrofitted beam 
Table 3: Summary of results for pre-fatigue monotonic loading.

\begin{tabular}{|c|c|c|c|c|}
\hline & $\begin{array}{r}\text { Intact RC } \\
\text { beam (EXP) }\end{array}$ & $\begin{array}{r}\text { Intact RC } \\
\text { beam (FE) }\end{array}$ & $\begin{array}{r}\text { CFRP-retrofitted } \\
\text { RC beam (EXP) }\end{array}$ & $\begin{array}{r}\text { CFRP-retrofitted } \\
\text { RC beam (FE) }\end{array}$ \\
\hline Load of the initial cracking (limit of elastic behavior) (kN) & 14.4 & 15.7 & 12.8 & 21.4 \\
\hline Mid-span deflection of the initial cracking $(\mathrm{mm})$ & 0.35 & 0.28 & 0.45 & 0.32 \\
\hline Peak load $(\mathrm{kN})$ & 64.7 & 66.5 & 85.8 & 87.7 \\
\hline Maximum deflection (mm) & 2.93 & 2.94 & 2.76 & 2.8 \\
\hline
\end{tabular}

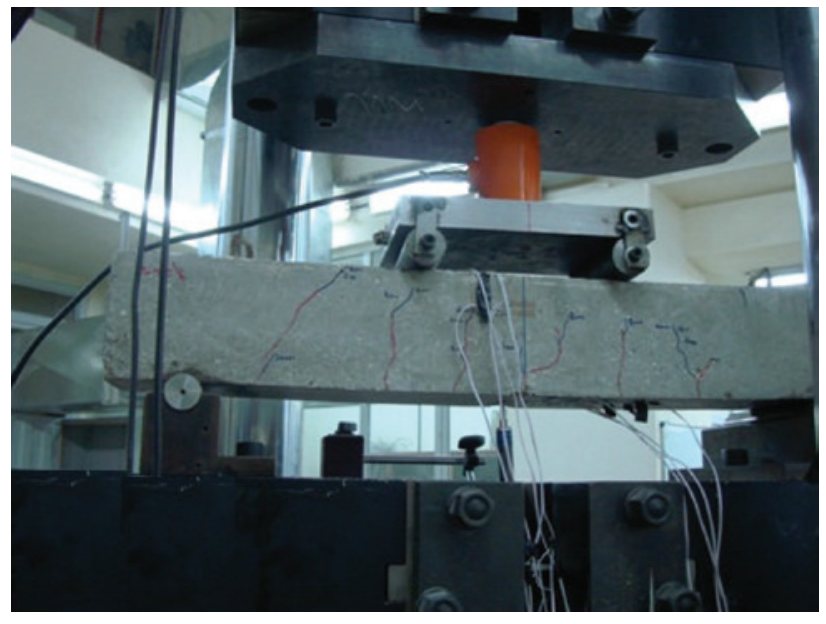

Figure 10: Experimental and FE analyses of RC specimens under fatigue loading at cycle 50,000.

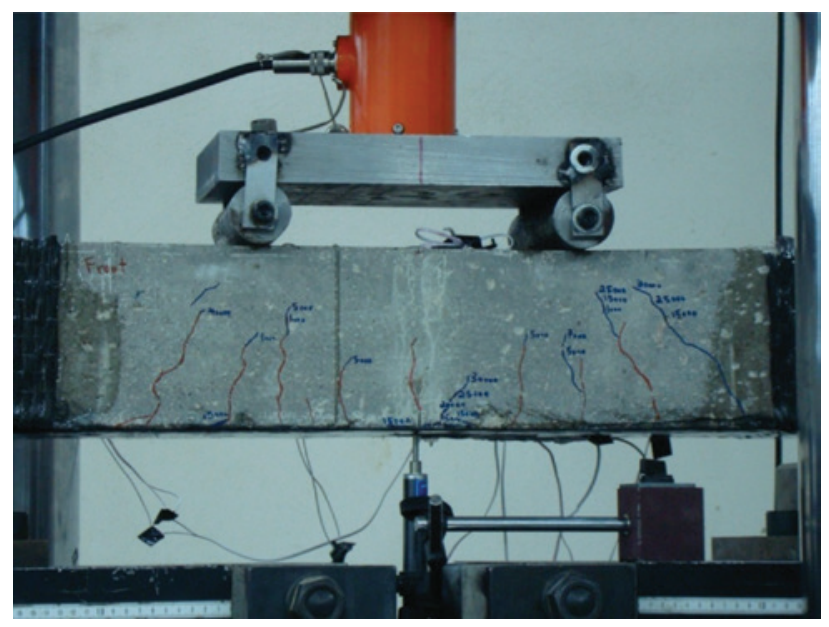

Figure 11: Experimental and FE examinations of CFRP-retrofitted RC specimens under fatigue loading at cycle 50,000.

at the tension face on the CFRP sheet slightly increased. As shown in Figure 13, as the load cycle approached the $20,000^{\text {th }}$ cycle, CFRP longitudinal strain increased in both minimum and maximum ranges, decreased suddenly, and then marginally increased until the $50,000^{\text {th }}$ cycle. According to the experimental observations, this
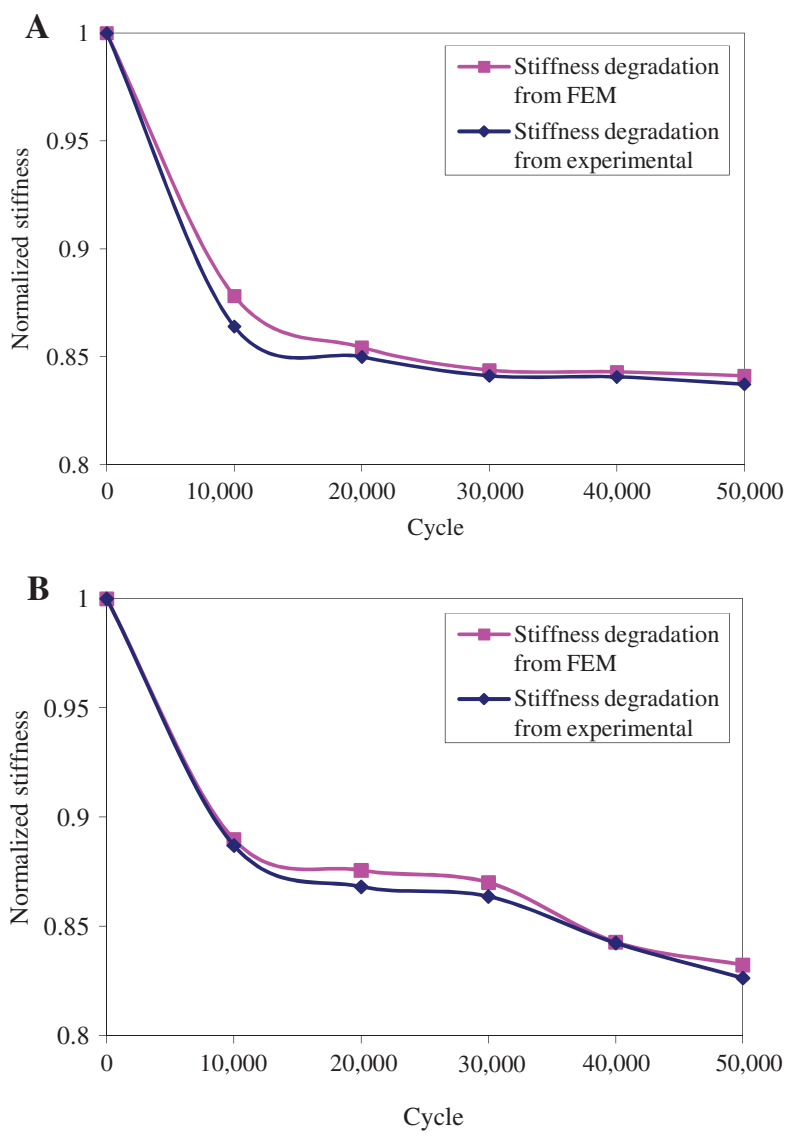

Figure 12: Normalized stiffness versus number of load cycles for (A) RC beams and (B) CFRP-retrofitted RC beams.

incidence occurred as a result of local debonding near the mid-span of the beam, which is attributed to the initial inserted notch.

The inter-laminar stresses in the adhesive layer and tensile steel rebar were calculated during load cycles. The results are illustrated in Figures 14 and 15. The longitudinal normal stresses were much higher than the shear stresses in the adhesive layer (Figure 14). However, parameter that identifies the debonding process is the maximum principal stress. The last cycles predicted for fatigue testing of RC and CFRP-retrofitted RC beams are illustrated in Figure 9E. As can be seen, the two modes 


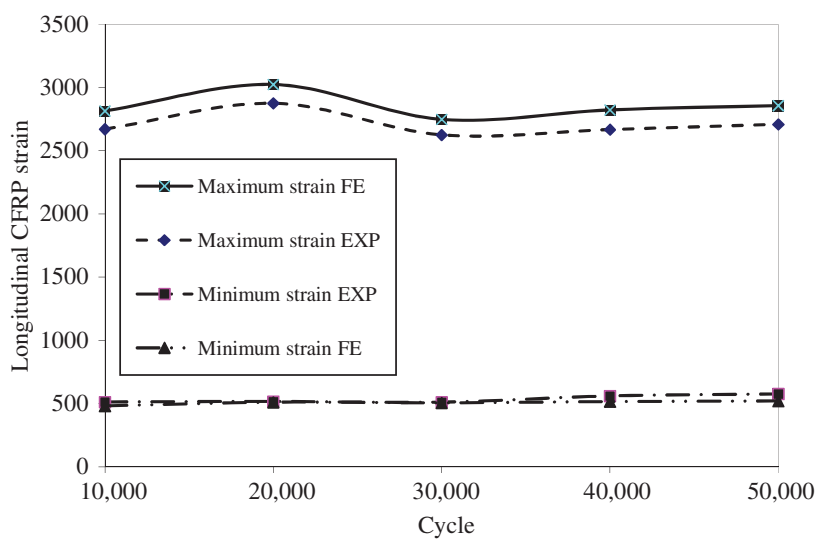

Figure 13: Variation in the longitudinal strain of CFRP at mid-span versus load cycle.

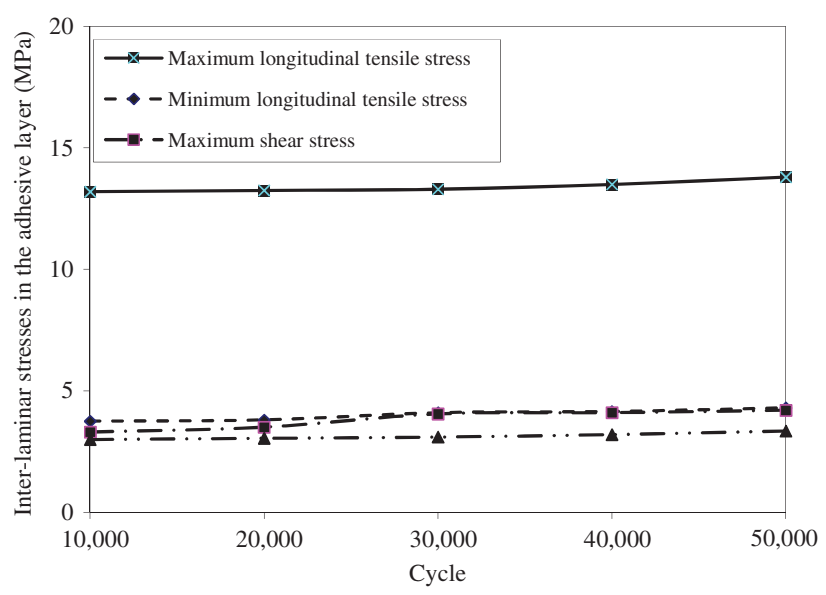

Figure 14: Variations in the shear and longitudinal tensile stresses in the adhesive layer at mid-span (FEM approach).

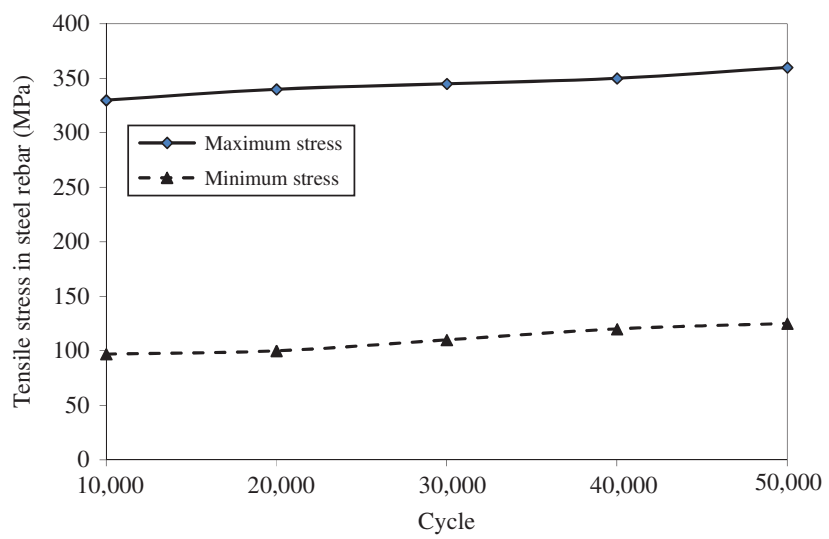

Figure 15: Variation in the longitudinal tensile stresses of steel rebars at mid-span in CFRP-retrofitted RC beams (FEM approach).

of failure that would result in specimen failure at the last cycle yielded of steel rebars and debonding of CFRP layer from the concrete substrate.

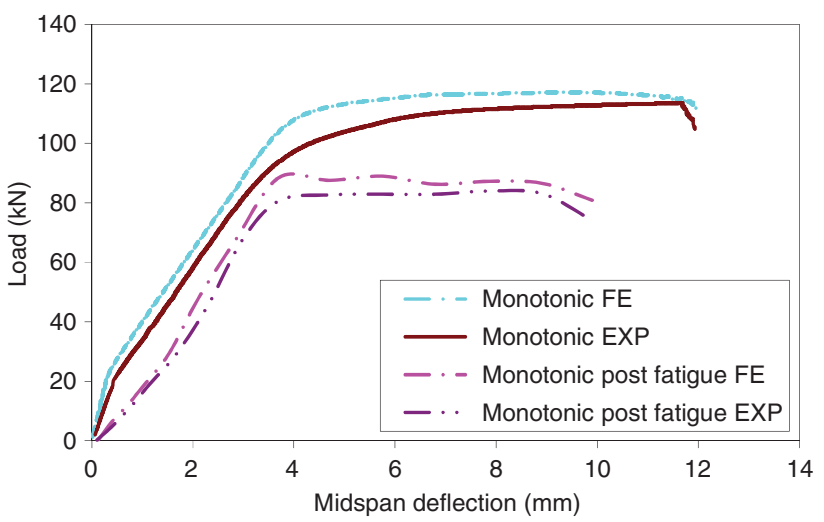

Figure 16: Comparison of monotonic and post-fatigue monotonic load-deflection curves of RC specimens obtained by FE and experimental analyses.

\subsubsection{Post-fatigue monotonic loading}

Load deflection curves for the control beam before and after applying various intervals of fatigue load cycles are shown in Figure 16. To assess the damage accumulation in the mid-span of each beam, the permanent mid-span deflections were recorded after different numbers of fatigue load cycles. The ultimate deflections of the control beams were significantly smaller than the deflection of the beams recorded prior to the fatigue loading tests. In other words, the ductility of un-strengthened RC beams was substantially larger than the ductility of control beams under static monotonic loading after 50,000 cycles, as shown in Figure 16. Furthermore, the flexural stiffness of the latter case almost diminished after post-fatigue loading with respect to the pre-fatigue stiffness. Comparing the FEM prediction with the experimental measurements, the accuracy of the numerical analysis would be

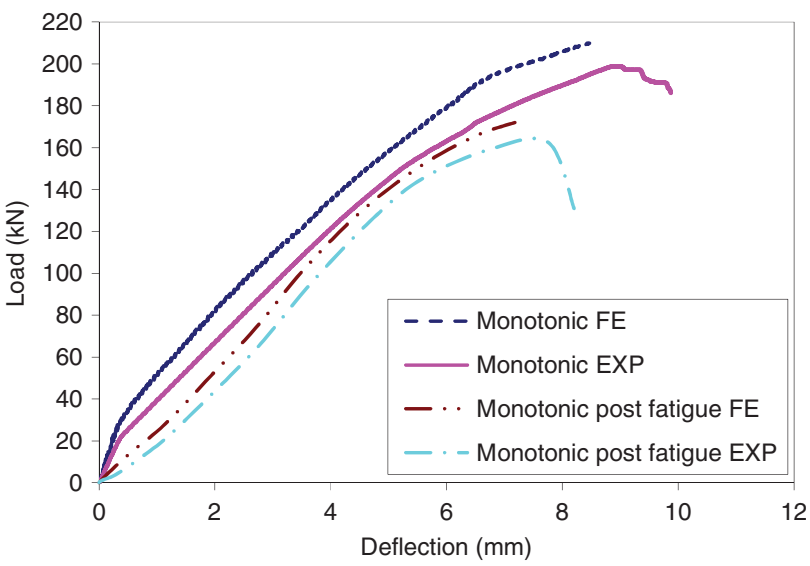

Figure 17: Comparison of monotonic and post-fatigue monotonic load-deflection curves of CFRP-retrofitted RC specimens obtained by $\mathrm{FE}$ and experimental examinations. 
verified. The same comparison between the experimental data and the FE analysis was made for the CFRP strengthened RC beams in Figure 17. For these cases, an initial increase in deflection was observed at the beginning of the cyclic loading. The ultimate load was reduced by $23 \%$ for specimens that experienced cyclic fatigue loading. The difference between the ultimate deflection of the CFRP-retrofitted and reference RC beams before and after fatigue cycling loading was highly pronounced, as shown in Figures 16 and 17.

Contours of maximum principal plastic strain along the adhesive layer are depicted in Figure 18. As

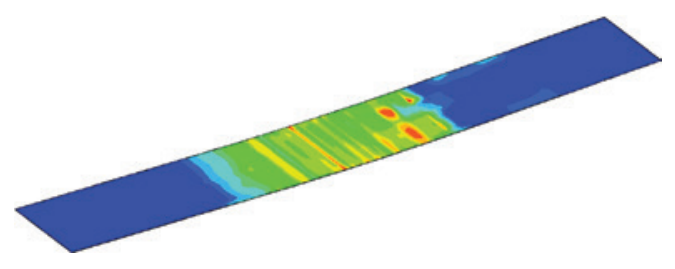

Figure 18: The distribution of plastic strains along the adhesive layer of a CFRP-retrofitted RC beam, as determined using FE analysis after the last cycle, which resulted in debonding of the adhesive layer from the concrete substrate. can be seen, the intensity of the strain formed around the middle part of the beam resulted in debonding of the adhesive layer from the concrete substrate. Meanwhile, Figure 19 illustrates the mid-span deflection versus fatigue load cycle for RC and CFRP-retrofitted RC beams that were obtained from experimental measurements and FE analysis. As previously mentioned, up to 50,000 cycles were evaluated both experimentally and FE analysis. After that and up to specimen failure, only results from FE analysis are presented. Generally, the FE curves are consistent with the experimental measurements up to cycle 50,000. From the FE analysis, it can be observed that the mid-span deflections increased slightly up to specimen failure. The modes of failure were previously discussed, and the amplitude of $\mathrm{RC}$ beams was observed to be lower than the amplitude of CFRP-retrofitted RC beams (6.5-65 kN to $8.5-85 \mathrm{kN})$. Intact RC beams had higher ultimate deflections (lower limit: $7.5 \mathrm{~mm}$, upper limit: $9.46 \mathrm{~mm}$ ) compared with the CFRP-retrofitted beams (lower limit: $8.8 \mathrm{~mm}$, upper limit: $11 \mathrm{~mm}$ ). During the last cycle, failure occurred almost immediately after a sudden increase in deflection, as shown in Figure 19.

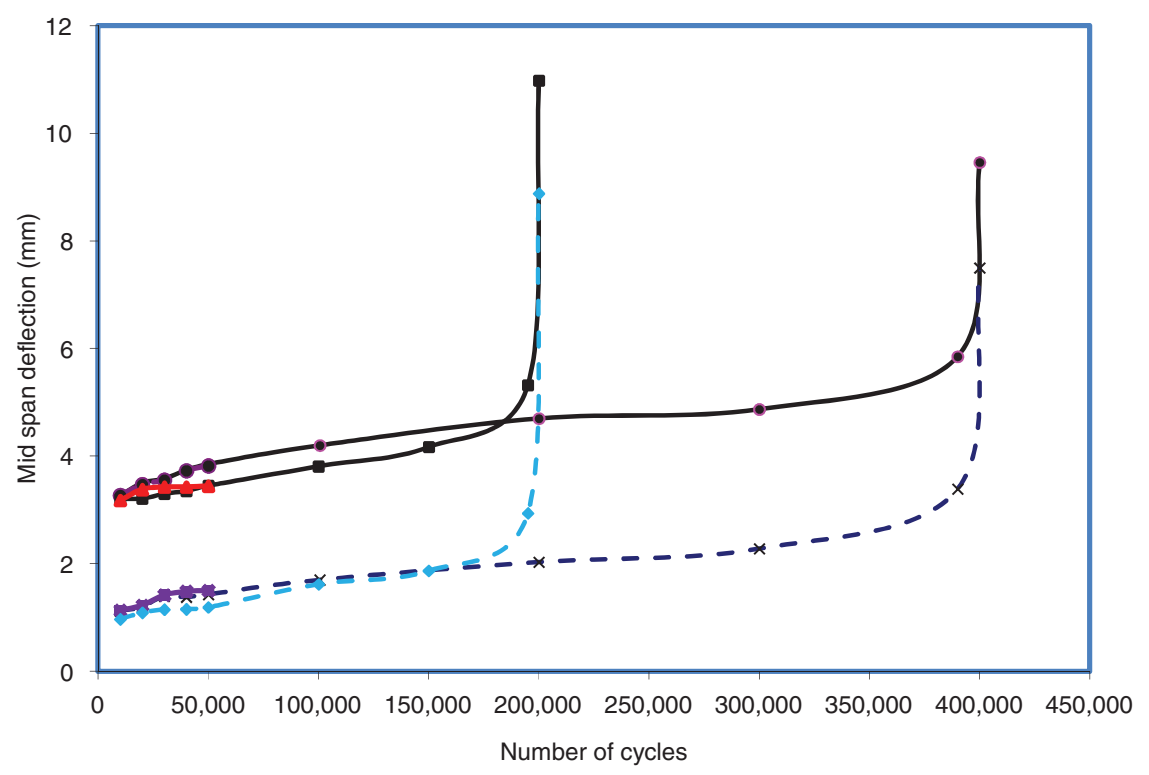

$$
\begin{aligned}
& - \text { CFRP retrofitted } \mathrm{RC} \text { beam upper limit FE } \\
& -*-\text { CFRP retrofitted } \mathrm{RC} \text { beam lower limit } \mathrm{FE} \\
& -- \text { CFRP retrofitted } \mathrm{RC} \text { beam upper limit experimental } \\
& - \text { CFRP retrofitted } \mathrm{RC} \text { beam lower limit experimental } \\
& \rightarrow-\mathrm{RC} \text { beam upper limit FE } \\
& --\mathrm{RC} \text { beam lower limit } \mathrm{FE} \\
& \rightarrow-\mathrm{RC} \text { beam upper limit experimental }
\end{aligned}
$$

Figure 19: Mid-span deflection versus number of cycles for all the specimens used in the experimental and FE examinations. 


\subsection{Discussion of nonlinear finite element analysis (NLFEA) on interfacial stresses}

In the previous sections, NLFEA was validated by experimental measurements. In this section, the study focuses on the variations of stresses in the interfacial adhesive layer, which play a significant role in the failure of CFRP-strengthened RC beams. Prior to crack formation in concrete, tensile stresses in the CFRP layer cause mild interfacial shear stresses in the adhesive layer. Full composite action is achieved between the CFRP reinforcement and concrete up to initial failure. To evaluate the bond characteristics between the concrete and CFRP reinforcement, the interfacial stress components were predicted using NLFEA. Figure 20A-D show the distribution of stress along the length of CFRP-retrofitted RC beams using the mid-span as the origin. The interfacial stress components, including normal stress, $\sigma_{\mathrm{yy}}$; shear stress, $\tau_{\mathrm{yz}}$; normal stress, $\sigma_{\mathrm{zz}}$; and maximum principal stress, where $\mathrm{y}$ is the vertical direction and $\mathrm{z}$ is the beam longitudinal direction, are plotted for various cyclic fatigue loading numbers to illustrate the change in stress distribution with increasing load cycle number. The normal and principal stress distribution are proportional to the moment diagram of all fatigue load cycles. Based on the results, maximum stress was observed at the mid-span and slightly declined in both directions before suddenly decreasing at the end supports. This reduction was more pronounced in the last load cycle, which was over 400,000. The variation of interfacial shear stress, $\tau_{\mathrm{yz}}$, was approximately the same for all fatigue load cycles, except around the notch near the mid-span. However, as the number of load cycles increased, a significant fluctuation was observed in the shear stress distribution along the RC beam, as shown in Figure 20.

Cracking behavior of simply supported RC beams strengthened with CFRP sheets under four-point flexural loading with fatigue nature is shown in Figures 21A-24A. As can be seen, initial cracks at the concrete portion originated from the mid-span around the notched area and propagated longitudinally within the maximum moment zone. The distribution of crack formation was symmetrical on both sides from the center. The cracks initiated perpendicular to the center at the mid span section and extended to the top surface. Cracks also initiated and developed outside of the applied load positions. The numerical results also indicate that stabilized flexural cracks occurred with load cycles, and crack widths further increased with fatigue load cycles.
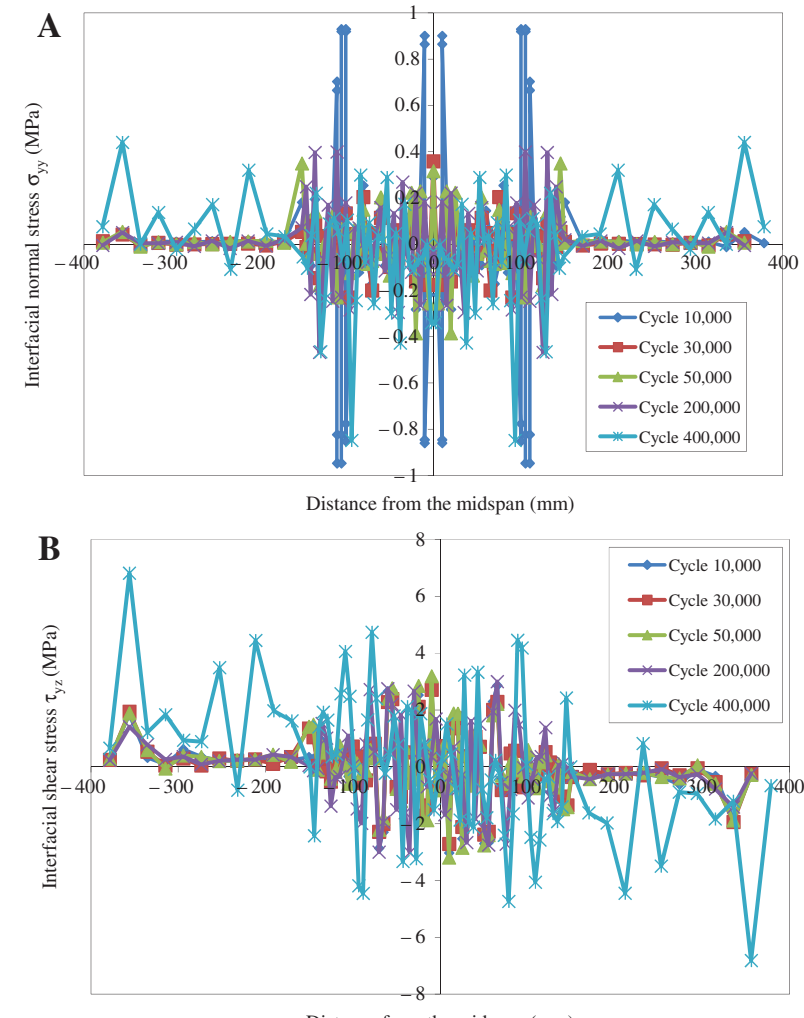

Distance from the midspan (mm)
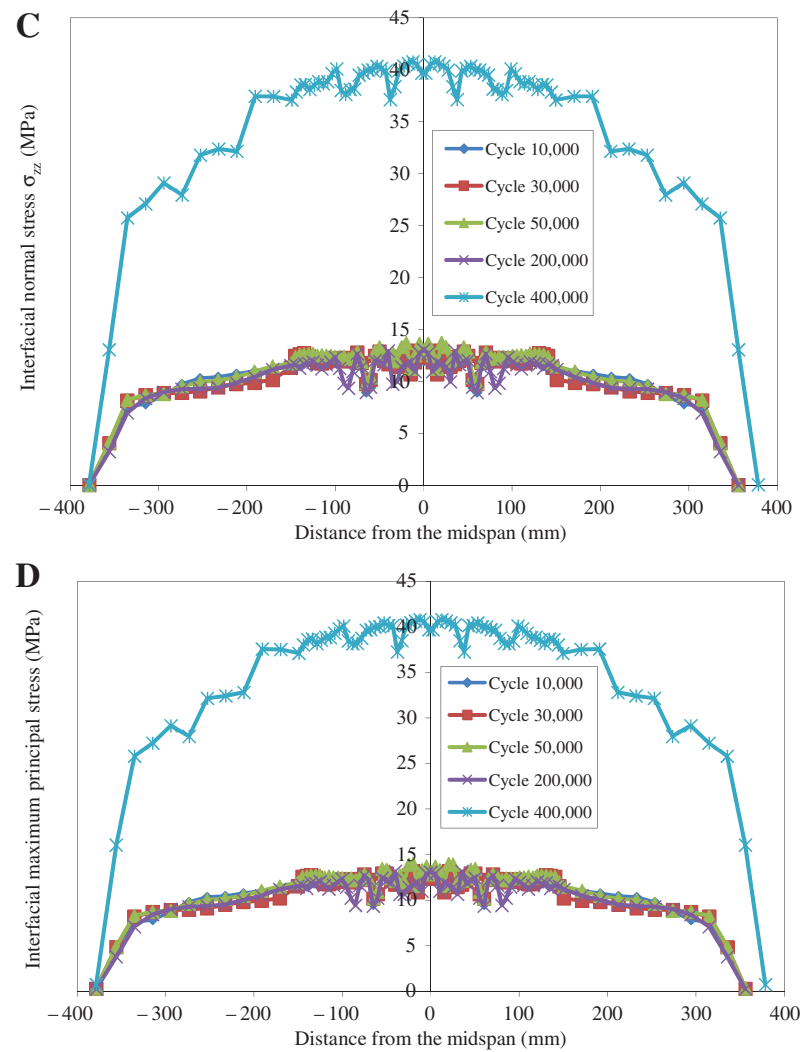

Figure 20: Variations of stress contours along the interfacial adhesive elements versus fatigue cycle number.

(A) Normal stresses $\sigma_{y y}$, (B) Shear stresses $\tau_{y z}$, (C) Normal stresses $\sigma_{z z}$, and (D) Maximum principal stresses. 


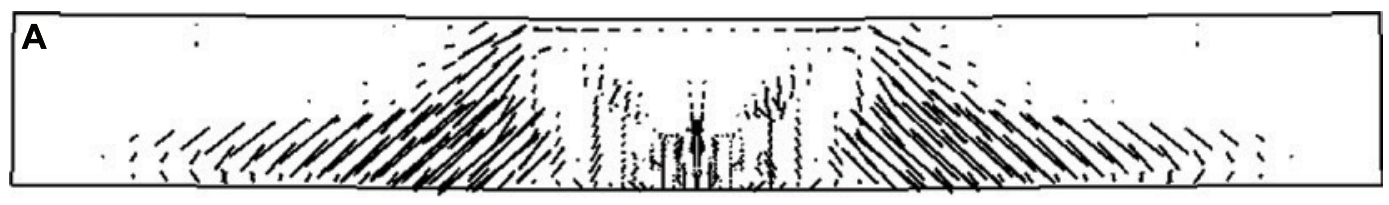

B
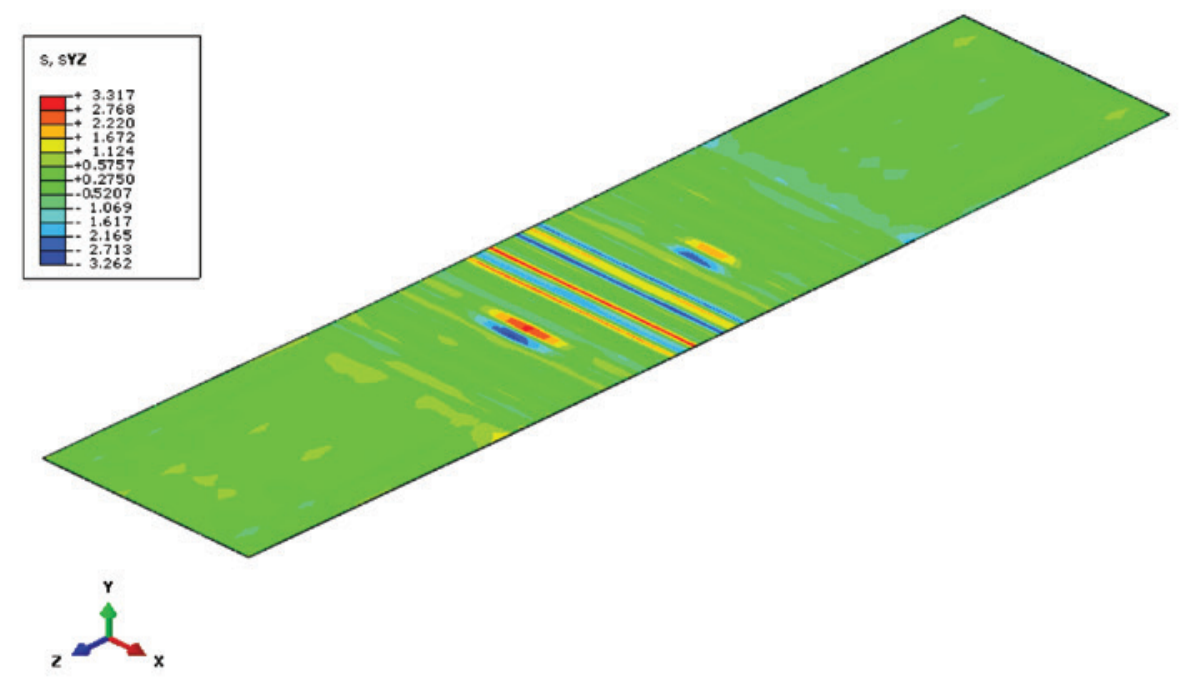

C

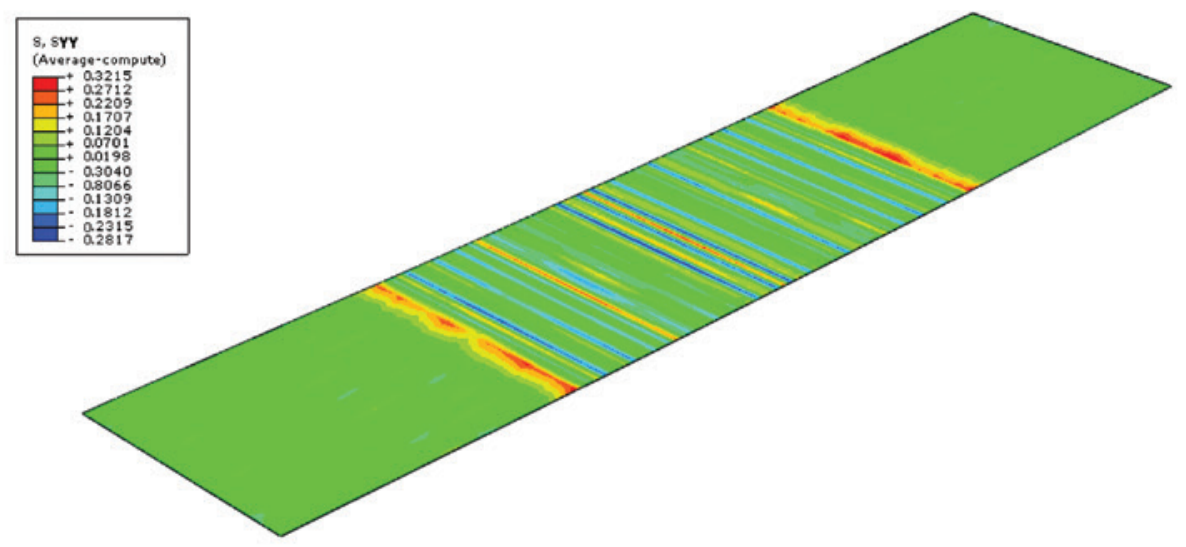<smiles>CC(C)C</smiles>

Figure 21: Distribution of (A) concrete cracking, (B) shear stresses in the adhesive layer, and (C) normal stresses in the adhesive layer of a CFRP-retrofitted RC beam after 10,000 cycles.

Stress contour values are in $\frac{\mathrm{N}}{\mathrm{mm}^{2}}$.

The distribution of interfacial stress component contours, $\tau_{\mathrm{yz}}$ and $\sigma_{\mathrm{yy}}$, between the CFRP and the concrete substrate in the bond layer is illustrated in Figures 21B-24B for different load cycles. As the number of load cycles increased, the interfacial stresses intensified and propagated from the mid-span zone within the longitudinal direction. Given that the normal stresses along the beam depth were minimal, an illustration of these stresses was omitted.

The direction and maximum magnitude of the principal stresses in the adhesive layer were predicted at cycles 10,000, 30,000, 50,000 and the last cycle of fatigue loading by NLFEA. These measurements are major parameters typically used to predict the mode of the 


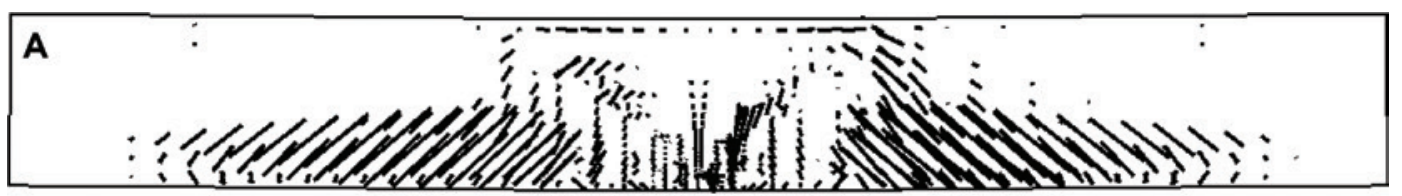

B

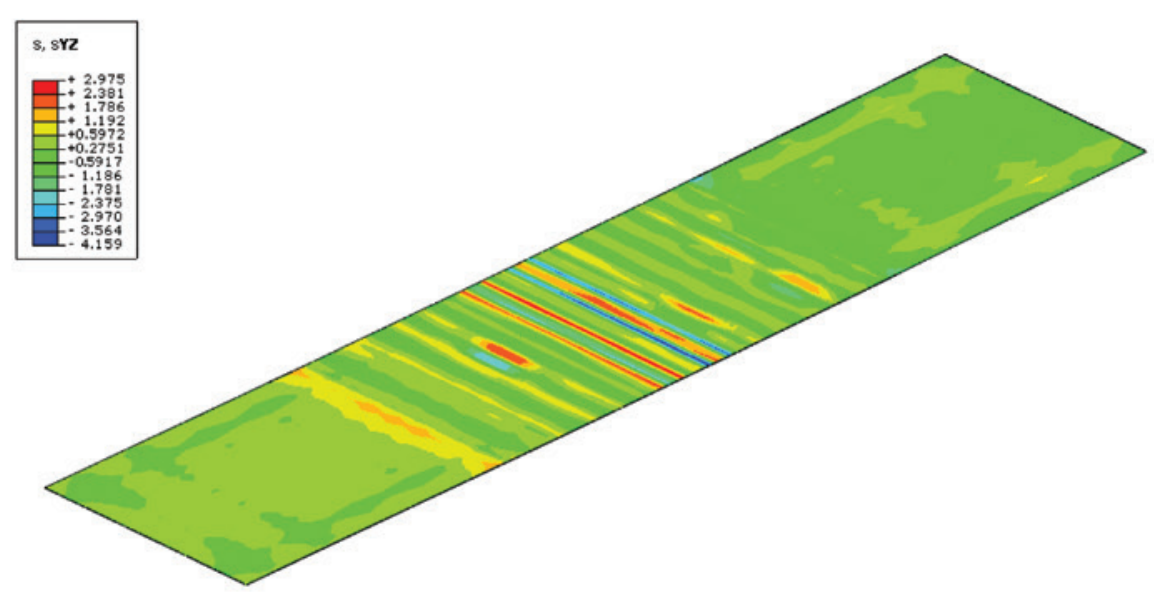<smiles>CC(C)[13CH3]</smiles>

C
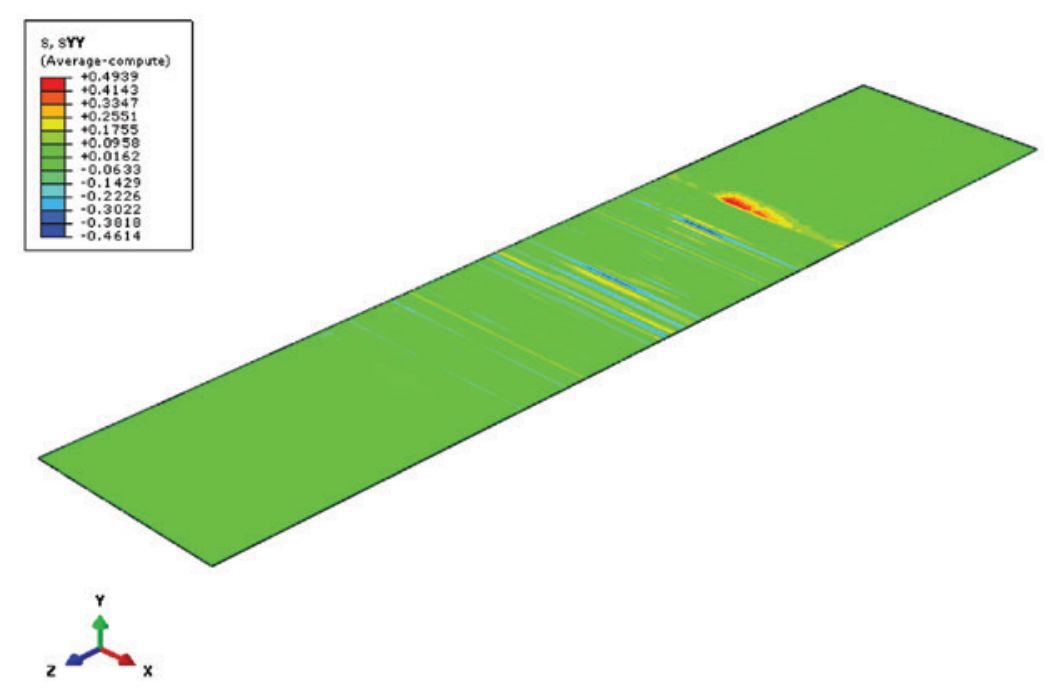

Figure 22: Distribution of (A) concrete cracking, (B) shear stresses in the adhesive layer, and (C) normal stresses in the adhesive layer of a CFRP-retrofitted RC beam after 30,000 cycles.

Stress contour values are in $\frac{N}{m m^{2}}$.

debonding failure mode of the CFRP-concrete junction and the direction of crack growth for different levels of cyclic fatigue loading.

The variation of maximum principal stress contour along the mid-row of the adhesive layer versus load cycle is illustrated in Figure 25. As previously explained, this component of interfacial stress is significant and can result in debonding. Therefore, increasing the number of fatigue load cycles can change the direction of the interfacial maximum principal stress contours to a more vertical direction. This explains the increased probability of debonding in the adhesive layer. 


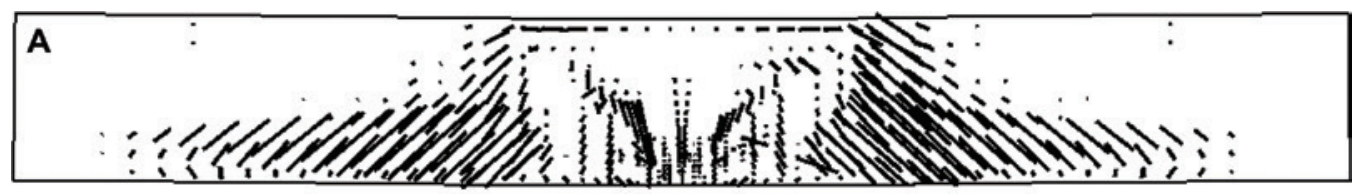

B

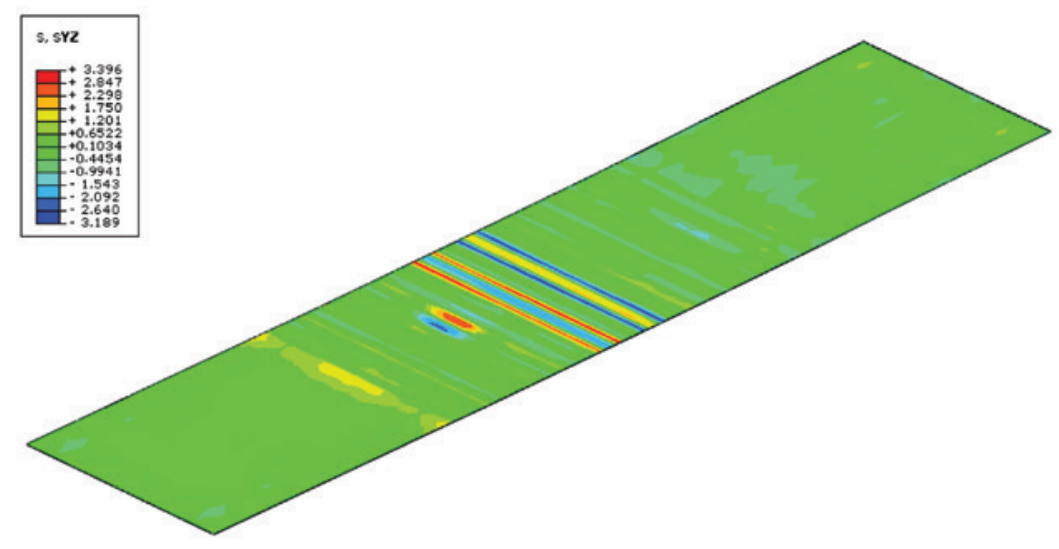<smiles>C[13CH][13C]([13CH3])I</smiles>

\section{C}

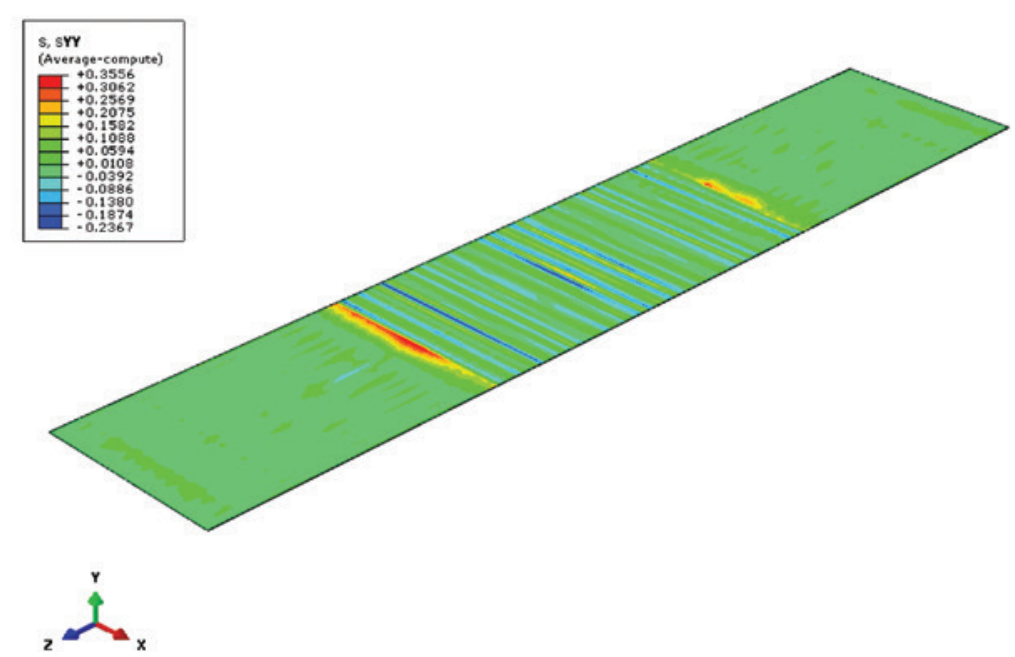

Figure 23: Distribution of (A) concrete cracking, (B) shear stresses in the adhesive layer, and (C) normal stresses in the adhesive layer of a CFRP-retrofitted RC beam after 50,000 cycles.

Stress contour values are in $\frac{\mathrm{N}}{\mathrm{mm}^{2}}$.

\section{Summary and conclusions}

The current paper presents fatigue response of CFRPstrengthened RC beams. Several conclusions can be drawn based on the experimental and nonlinear finite element analysis.

First, the main empirical relation predicted the degradation of Young's modulus for concrete, which was fitted to both RC and CFRP-retrofitted beams. The equation proposed in the current research to determine the degradation of Young's modulus for concrete was compared to previous works and is useful in fatigue design and analysis.

Second, for a large number of load cycles, i.e. more than 100,000, the RC beams demonstrated increased deflection. The load deflection, strain response, and degradation of flexural stiffness with load cycle number of the control and CFRP-retrofitted RC beams were presented as fatigue characteristics. The pre- and post-fatigue monotonic test results showed that the load deflection responses of beams with and without previous cycling were similar. 


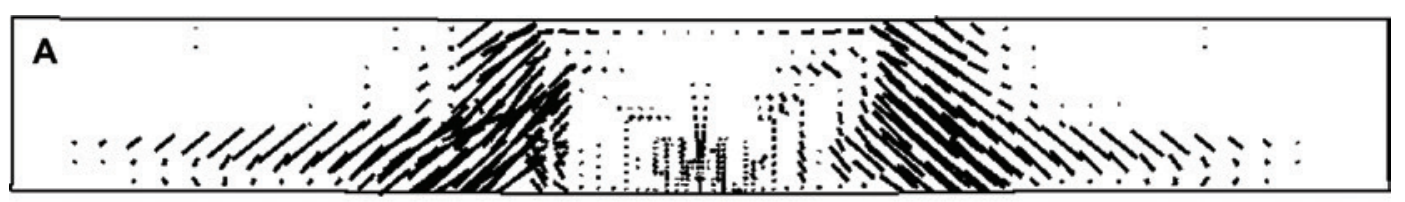

\section{B}

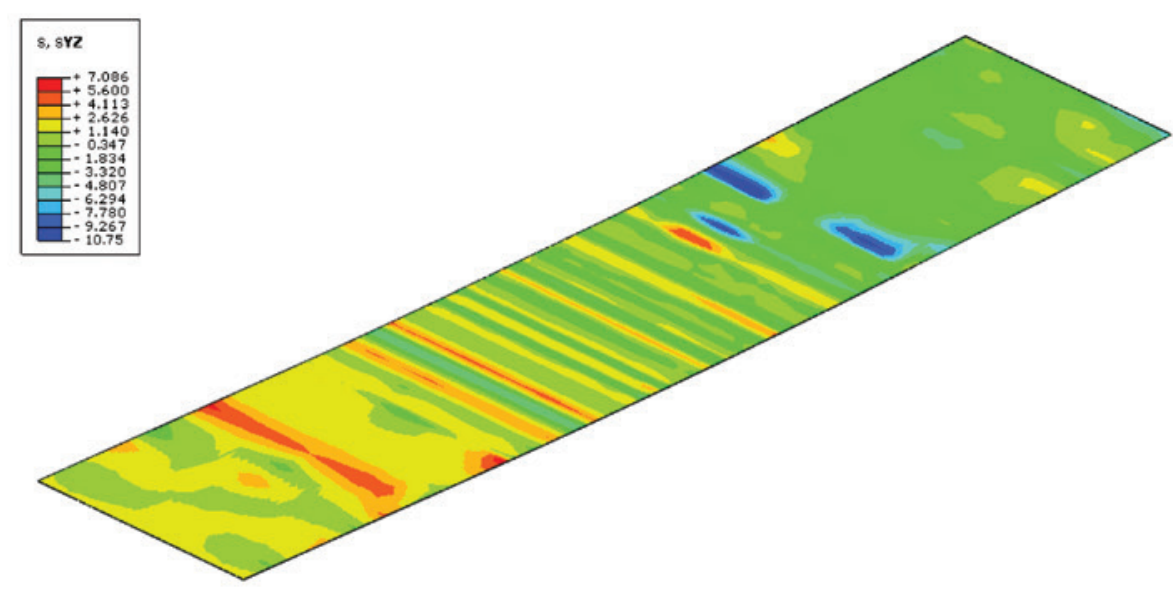<smiles>C[13CH][13CH]</smiles>

C

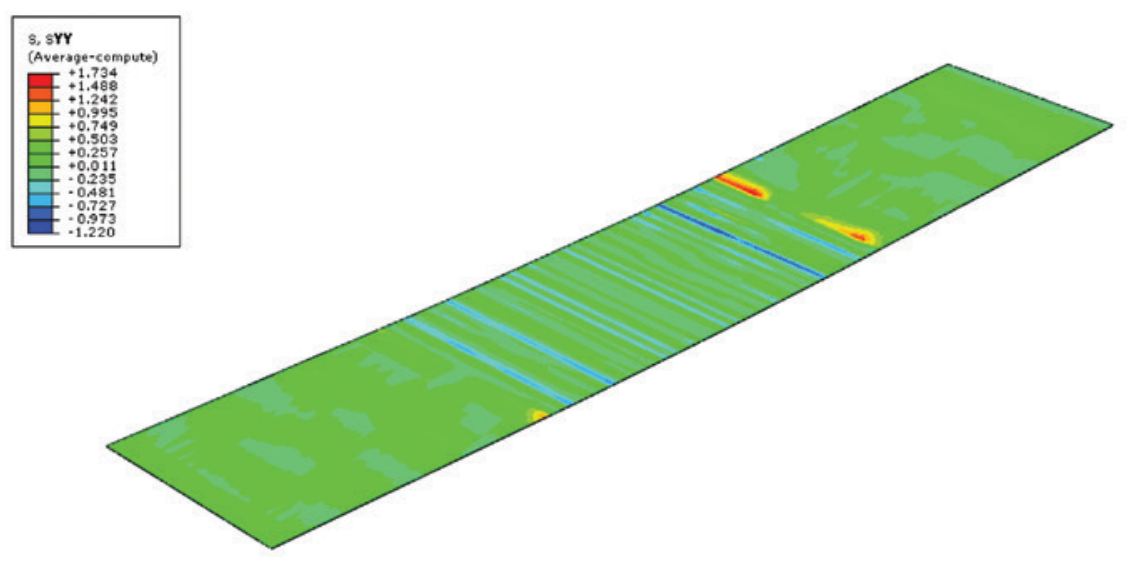<smiles>CC(C)C(C)C</smiles>

Figure 24: Distribution of (A) concrete cracking, (B) shear stresses in the adhesive layer, and (C) normal stresses in the adhesive layer of a CFRP-retrofitted RC beam after the last cycle.

Stress contour values are in $\frac{N}{\mathrm{~mm}^{2}}$.

Third, the variations in interfacial stress components along the longitudinal direction of the beams during fatigue hysteresis were illustrated to show an important criterion that predicted debonding in the adhesive layer between CFRP sheet and the concrete substrate. Damage occurred during the last cycle in the debonding mode due to the shear stress response of the CFRP-concrete interface.
To verify the experimental results, a simplified and practical finite element analysis using ABAQUS software was conducted. The damage characteristics, Young's modulus degradation and $\mathrm{S}-\mathrm{N}$ curves obtained from the experimental program for concrete were introduced as parameters for FEM analysis. In the current study, results obtained from $\mathrm{FE}$ analyses and experimental examinations were compared. The presented results collected 

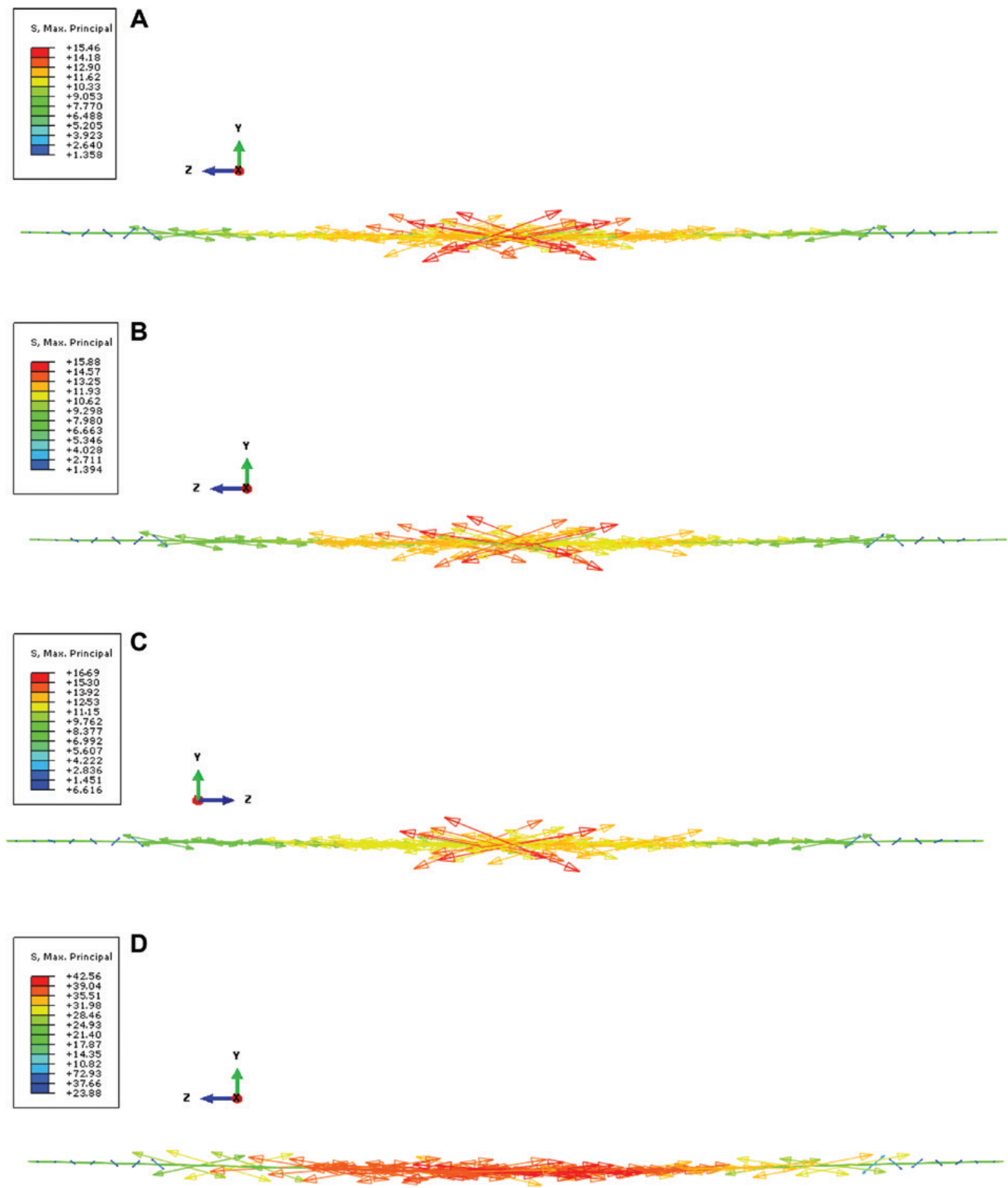

Figure 25: Illustration depicting the magnitude and direction of the maximum principal stresses along middle row of elements in the adhesive layer of a CFRP-retrofitted RC beam after the (A) $10,000^{\text {th }}$ cycle, (B) $30,000^{\text {th }}$ cycle, (C) $50,000^{\text {th }}$ cycle, and (D) last cycle.

Stress contour values are in $\frac{N}{\mathrm{~mm}^{2}}$.

from both experimental and FEM examinations consisted of typical load-deflection curves at the stages of pre-fatigue monotonic, cyclic fatigue and post-fatigue monotonic loadings, and stiffness degradation diagrams. All the FEM and experimental results were compared to one another, and the comparisons, indicated a relatively good agreement. Finally, FEM analysis was performed to predict fatigue cyclic failure of both intact and CFRP retrofitted RC specimens, and the achieved results were compared. 


\section{References}

[1] Varastehpour H, Hamelin P. Mater. Struct. RILEM. 1997, 30, 160-166.

[2] Meier U. Non-Metallic (FRP) Reinforcement for Concrete Structures, Japan Concrete Institute, 1997, 1, 41-56.

[3] Duthinh D. J. Compos. Constr. ASCE. 2004, 8, 59-69.

[4] Teng JG, Chen JF, Smith ST, Lam L. FRP-Strengthened RC Structures. John Wiley \& Sons: West Sussex, England, 2002

[5] Hu HT, Lin FM, Jan YY. J. Compos. Constr. ASCE. 2004, 63, 271-281.

[6] Goloti V, Spadea G, Swamy RN. J. Compos. Constr. ASCE. 2004, $8,104-122$

[7] Dong JF, Wang QY, Guan ZW. Eng. Struct. 2012, 41, 24-33.

[8] Jankowiak I. Arch. Civ. Mech. Eng. 2012, 12, 376-388.

[9] Zibara YN, Baluch MH, Sharif AM. Mater. Struct. 1995, 28, 518-525.

[10] Quantrill RJ, Hollaway LC, Thorne AM. Mag. Concrete. Res. 1996, 48, 343-351.

[11] Zou Y, Huchelbridge PE. J. Bridge. Eng. ASCE. 2007, 12, 237-245.

[12] ACl Committee 215R-74. Considerations for design of concrete structures subjected to fatigue loading. 2008.

[13] Derkowski W. Arch. Civ. Mech. Eng. 2006, 6, 33-47.

[14] Kmita A. Arch. Civ. Mech. Eng. 2007, 7, 5-19.
[15] Papakonstantinou CG, Balaguru N, Petrou MF. ACI Special Publication SP206: Concrete: Material Science to Application - A Tribute to Surendra P. Shah, 2002; SP206-03:41-60.

[16] Holmen J0, Fatigue of concrete by constant and variable amplitude loading, Vol. 75, ACI Publication, 1982, pp. 71-110.

[17] Ferrier E, Bigaud D, Clement JC, Hamelin P. Constr. Build. Mater. 2011, 25, 539-546.

[18] Ferrier E, Quiertant M, Benzarti K, Hamelin P. Compos. Part B Eng. 2010, 41, 354-362.

[19] Macgregor LG. Reinforced Concrete Mechanics and Design. Prentice-Hall: NJ, 2000.

[20] Owen DRJ, Figueiras JA, Damjanic F. Comput. Methods Appl. Mech. Eng. 1983, 41, 323-366.

[21] Jakobsen AK. Bulletin no 70-1, NTH Institut for betonkonstruksjoner, Trondheim.

[22] Balagru B, Shah SP. Fatigue Concr. Struct. ACI. 1982, SP-75, 153-176.

[23] Thorenfeldt E, Tomaszewicz A, Jensen JJ. Proceeding, Symp. on the Utilization of High Strength Concrete, Tapir, Trondheim, Norway, 1987, 149-159.

[24] Taljsten B. J. Mater. Civ. Eng. ASCE 1997, 9, 206-212.

[25] Ferrier E, Bigaud D, Hamelin P, Bizindavyi L, Neal KW. Mater. Struct. 2005, 38, 39-46.

[26] Papakonstantinou C, Petrou M, Harries K. J. Compos. Constr. ASCE. 2001, 5, 246-253.

[27] Helgason T, Hanson JM. Proceeding, Abeles Symp. on Fatigue of Concrete, American Concrete Institute, 1974, Detroit, 107-138. 